\title{
Mathematical modelling of the Germasogeia aquifer
}

\author{
Graham Benham* Peter Frolkovič ${ }^{\dagger} \quad$ Tihomir Ivanov $^{\ddagger}$ \\ ${\text { Raka Mondal* Sourav Mondal* }{ }^{*} \quad \text { Vivi Rottschäfer }}^{\S}$ \\ Katerina Kaouri ${ }^{\pi}$
}

July 31, 2017

Team participants

Demetrios Papageorgiou, Department of Mathematics, Imperial College London, United Kingdom

Christos Nikolopoulos, Department of Mathematics, University of the Aegean,

Greece

Hilary Ockendon, Mathematical Institute, University of Oxford, United Kingdom

Paul Christodoulides, Department of Electrical Engineering, Computer

Engineering and Informatics, Cyprus University of Technology, Cyprus

Asbjørn Nilsen Riseth, Mathematical Institute, University of Oxford, United

Kingdom

Andrew Lacey, School of Mathematical \& Computer Sciences, Heriot-Watt University, United Kingdom

The problem was presented by

Natasa Neokleous, Water Development Department, Cyprus

at the 125th European Study Group with Industry (ESGI125)

(1st Study Group with Industry in Cyprus, www.esgi-cy.org)

\begin{abstract}
Two challenges related to improving the management of the Germasogeia aquifer were presented to the Study Group by the Cyprus Water Development Department (WDD), the public organisation responsible for managing the water resources in Cyprus. The first challenge was how to optimally recharge the aquifer in order to compensate for the extraction of drinking and irrigation water whilst preventing sea water intrusion. In order to address this challenge we developed model for the water in the aquifer. Note that by exploiting the

*Mathematical Institute, University of Oxford, United Kingdom, benham@maths.ox.ac.uk

${ }^{\dagger}$ Department of Mathematics and Descriptive Geometry, Slovak University of Technology in Bratislava, Slovakia, peter.frolkovic@stuba.sk (corresponding author)

${ }^{\ddagger}$ Faculty of Mathematics and Informatics, Sofia University, Bulgaria, tbivanov@fmi.uni-sofia.bg

§Mathematical Institute, Leiden University, The Netherlands, vivi@math.leidenuniv.nl

`Cyprus University of Technology, Cyprus, katerina.kaouri@cut.ac.cy
\end{abstract}


long, thin nature of the aquifer we only develop two-dimensional models in this work. We first develop a simple model based on Darcy flows for porous media which gives the water table height for given dam seepage rate, recharge and extraction rates; we neglect seawater intrusion. We then use the steady version of this model to develop an optimized recharge strategy with which we can identify minimal recharge required for a desired extracted water volume such that the minimum prescribed water table is respected. We explore 4 different scenarios and we find that in certain cases there can be a considerable reduction in the amount of recharged water compared to the current empirical strategy the Water Development Department is employing, where water is recharged and extracted in equal proportions. To incorporate the effects of seawater intrusion, which can be very damaging to the water quality, we next develop transient twodimensional models of saturated-unsaturated groundwater flow and solve them numerically using the open source software SUTRASuite and the commercial package ANSYS FLUENT; the position of the water table and the seawaterfreshwater interface are determined for various extraction/recharge strategies. Data from the WDD are used in some of the simulations. The second important challenge we were asked to look at was to predict the transport of pollutants in the aquifer in the case of an accidental leakage. An advection-diffusion equation for the contaminant concentration is introduced and simulations are undertaken using the commercial package COMSOL. The concentration profiles of the contaminant are studied and we find that the effect of contamination varies depending on where the contamination site is; the closer the contamination site is to the dam, the larger the extent of contamination will be.

KEYwORDS: groundwater flow, Darcy flow, water table, optimal recharge, water management, contaminant transport

\section{Introduction}

During the Study Group week we worked on two challenges related to the Germasogeia aquifer, presented by the Cyprus Water Development Department (abbreviated WDD from now on). The first challenge is how to optimally recharge the aquifer and the second challenge is modelling the transport of contaminants from an accidental leakage in the aquifer.

The Germasogeia aquifer is an alluvial aquifer, consisting of loose material, which enables effective filtering of the water. It lies along the Germasogeia river valley and extends from the Germasogeia dam to the coast. It is $5.5 \mathrm{~km}$ long and has an area of $3 \mathrm{~km}^{2}$. It lies under an urbanised area, the Limassol-Nicosia highway, local important roads and several main pipelines. Its width varies from $100 \mathrm{~m}$ to $800 \mathrm{~m}$, and its depth from $35 \mathrm{~m}$ upstream, near the dam, to $55 \mathrm{~m}$ near the sea-see Figure

1 for a cross section of the aquifer. The Germasogeia aquifer is the first aquifer in Cyprus that has been used as a natural water treatment plant, and it is currently the most intensively exploited aquifer in the country. Since 1982, the WDD in the district of Limassol has been using water from the Germasogeia dam to recharge the Germasogeia aquifer, with controlled releases on the surface of the aquifer, at four recharge points. See Figure 2 (left) for the locations of recharge points, indicated by the large green circles.

After natural purification, the 'treated' groundwater is pumped out of the aquifer 


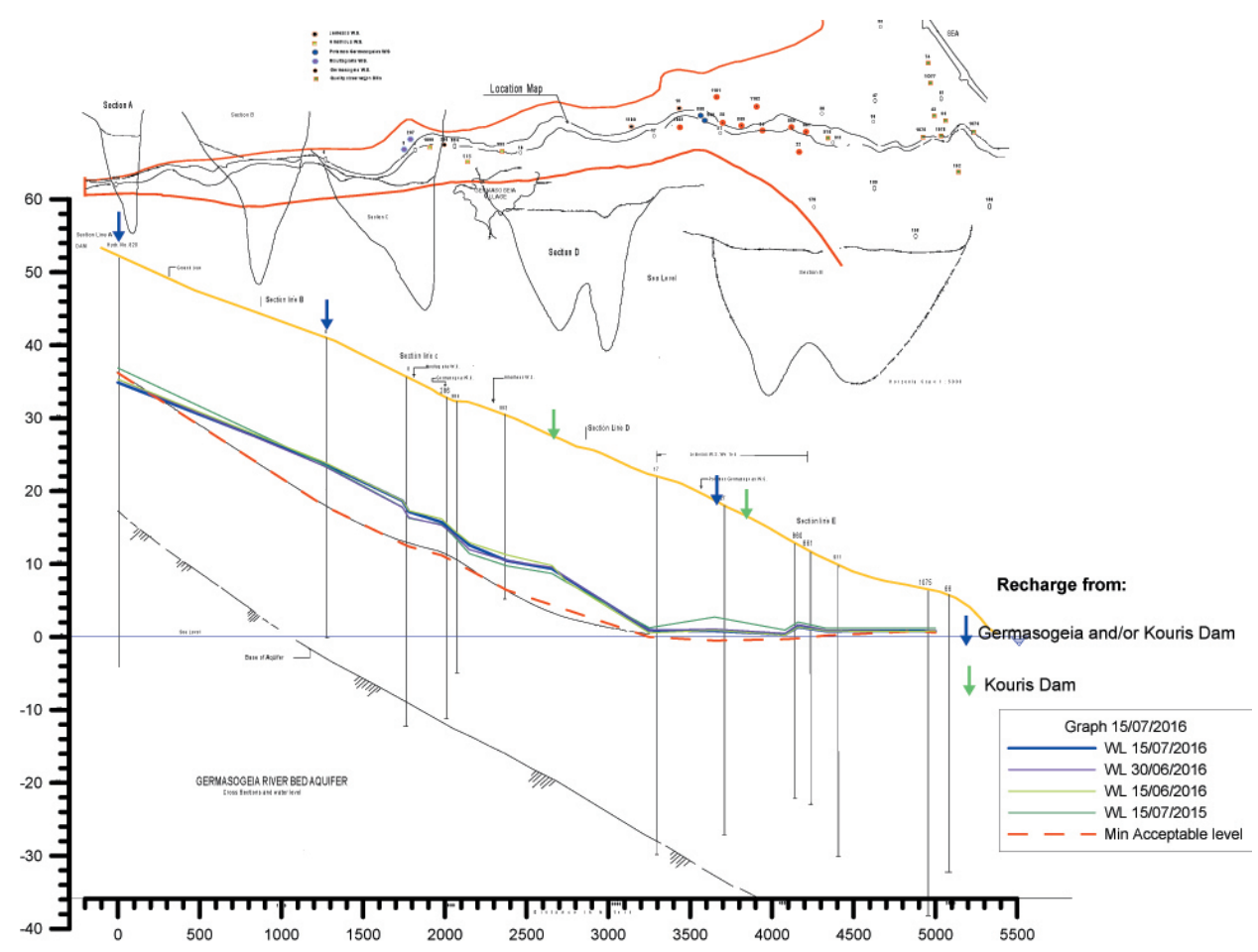

Figure 1: A cross section of the Germasogeia aquifer. The red dotted line is the minimum acceptable water table level and the other 4 colored curves are water table levels at the dates specified in the legend. The downward arrows represent the recharge points. The 13 thin grey vertical lines represent boreholes used for observation.

through boreholes to supply domestic water to the greater Limassol area. No further water treatment is carried out except chlorination of the water tanks. At the moment, there are 19 boreholes in operation - see Figure 2 Left for the locations of the boreholes (indicated with smaller blue circles). The extraction rates from these boreholes vary from 40 to $130 \mathrm{~m}^{3}$ /hour. The total volume of extracted water varies from 5-7 million $\mathrm{m}^{3}$ per year.

The aquifer has impermeable boundaries at the east and west and an impermeable base, the bedrock where no water can enter or exit. Water enters the aquifer from the dam; it seeps through the dam into the aquifer. The sea is located at the south boundary. There, fresh water can exit the aquifer and salt water can enter the aquifer. One important objective for the effective management of the aquifer is to avoid both of these scenarios. It is more important to avoid seawater intrusion because if this happens the groundwater can no longer be used as drinking water. If the seawater enters it will leave the aquifer very slowly as the speed of the flow and also the slope of the aquifer are small. Moreover, when fresh water goes to the sea good drinking water, a precious commodity in dry Cyprus is wasted.

The report is organized as follows: in Section 2 we describe the two aquifer challenges in more detail. In Section 3 we develop a two-dimensional aquifer model based 

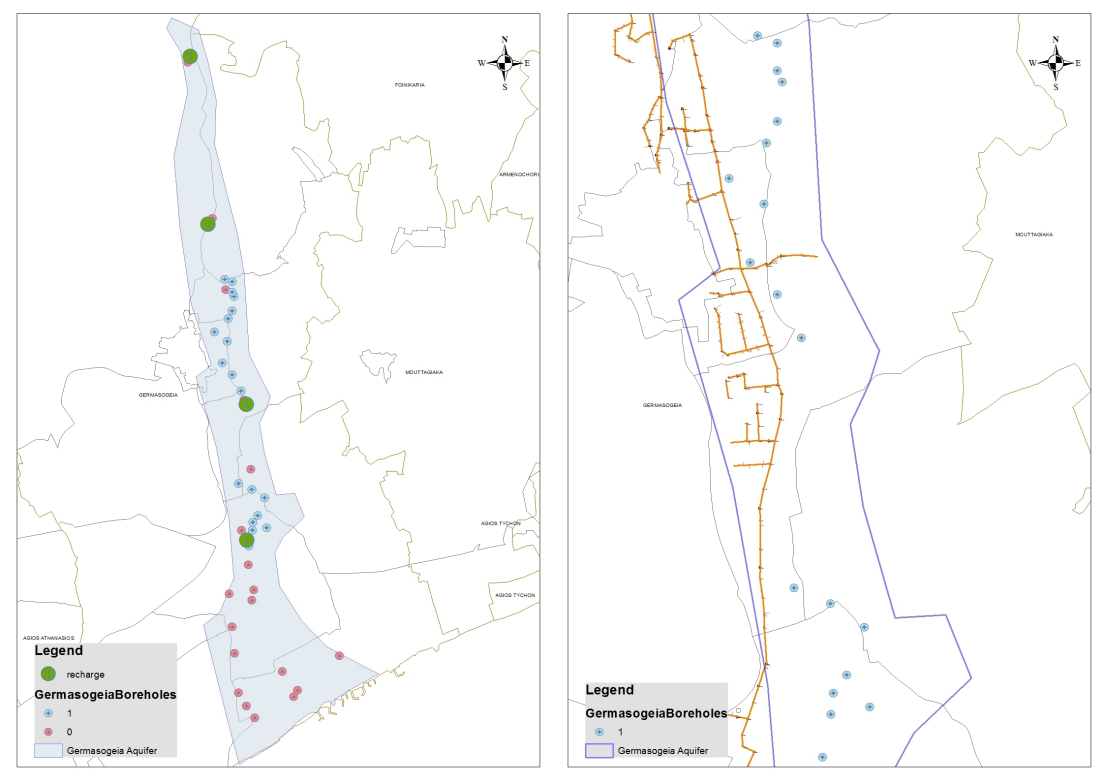

Figure 2: Top view of the aquifer. Left: the recharge points are indicated with large green circles and the extraction points indicated with small circles. Right: The location of the sewage system, indicated with orange.

on Darcy flow, and then use it to develop an optimal recharge strategy. In Section 4 , in order to study seawater intrusion, we develop a two-dimensional aquifer model based on saturated-unsaturated groundwater flow modelling with a variable water density, using the open source software SUTRASuite. In Section 5 we also apply the commercial software FLUENT to do more simulations of the flow in the aquifer. In Section 6, we examine contaminant transport and a related model is developed using the commercial software COMSOL Multiphysics. Finally, in Section 7 we summarise our conclusions and give some recommendations to the Water Development Department for follow-up actions and possibilities for further collaboration.

\section{Description of the challenges}

The main aims of the WDD for effectively managing the Germasogeia aquifer are: a) supply drinking water of acceptable quality to the greater area of Limassol b) protect the Germasogeia aquifer from seawater intrusion, and c) minimise groundwater losses to the sea.

In this connection, we were presented with the following two challenges for the Study Group week:

1. How can the effectiveness of the recharge process be maximised? At the moment there are four recharge points where water is inserted into the aquifer and 19 boreholes that pump water out. What is the optimal recharge protocol, i.e. for how long and at which locations should we recharge the aquifer while 
simultaneously

(a) protecting the aquifer from seawater intrusion, and

(b) minimising water losses to the sea?

2. If there is contamination by sewage or other pollutants, where will the pollution spread and how fast? What would this mean for the quality of the extracted water? Which measures should WDD take in order to minimise the contamination effects?

\section{Aquifer modelling with optimal recharge strategy}

In this section we derive an approximate, two-dimensional model based on Darcy flow which leads to an equation for the water table level in the aquifer. This model is related to the Dupuit model [1] for long and thin aquifers. This is a very good approximation for the Germasogeia aquifer since its length is $L \approx 5.7 \mathrm{~km}$ and its depth $H$ ranges from $35 \mathrm{~m}$ at the dam to $55 \mathrm{~m}$ at the sea. Also, the width of the aquifer is $W \approx 60 \mathrm{~m}$ except close to the sea where the aquifer becomes wider and as a first approximation we assume that the aquifer is a channel of uniform width and neglect any transverse flow along the width. The slope of the aquifer is small, around 4 degrees so we assume that the base of the aquifer is an inclined plane at constant slope. Additionally, we assume that the groundwater density, and viscosity and the ground permeability and hydraulic conductivity are all constants.

\subsection{Mathematical Model}

Therefore we consider a two-dimensional, gravity-driven flow in an inclined, porous aquifer. Beneath the aquifer lies a bed of impermeable bedrock and above it is the ground surface (see Figure 3). There is a saturated water table level at some height below the ground. Below the water table the aquifer is fully saturated and above it is approximately dry. Upstream of the aquifer is a dam which holds a large body of water behind a concrete barrier. The water seeps through the barrier at flow rate $Q$. Downstream of the aquifer, the water table meets the sea level at height $H_{b}$ above the bedrock. Water is extracted and injected into the aquifer at specific locations decided by the WDD. Let us choose our coordinate system such that the $x$ direction is parallel to the bedrock level, inclined at a constant angle $\alpha$ to the horizontal. In Figure 3, the tangent of $\alpha$ is given by $\tan \alpha=H / L$, where $H$ and $L$ are the length and elevation of the aquifer respectively. The angle $\alpha \approx 1 / 100$ radians, i.e. quite small since $\tan \alpha \approx H / L \approx 0.01$-mathematically -we denote this as $\alpha \ll 1$ (see Table 1) and we subsequently utilise it in the asymptotic analysis that follows in order to simplify our model. We also let $(u, w)$ denote the velocities in the $(x, z)$ directions respectively, and $p$ denotes the pressure. For flow in porous media, we shall use the 


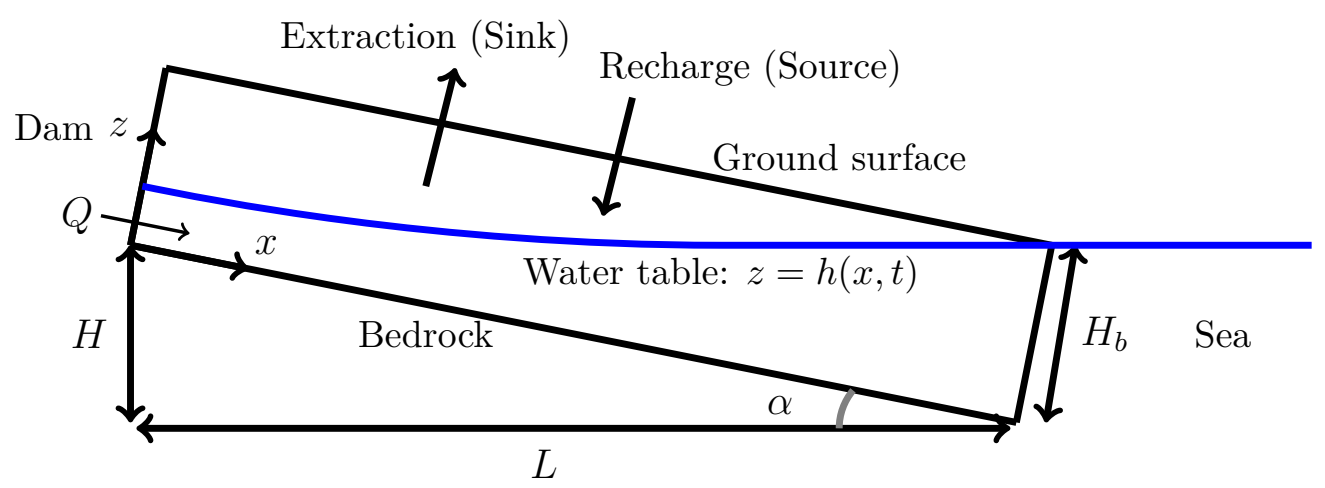

Figure 3: Schematic diagram of the long and thin, sloping aquifer related to the model equations (1)-(3). The water table level is indicated with the blue curve. The coordinate system $x$ and $z$ is taken respectively along and perpendicular to the bedrock, which is assumed to be a straight line. The inward looking arrow indicates a recharge point (a source in the model formulation), and the outward looking arrow indicates an extraction point (a sink in the model formulation); $\alpha$ is the angle to the horizontal level.

Darcy equations

$$
\begin{array}{r}
\frac{\partial u}{\partial x}+\frac{\partial w}{\partial z}=s(x, t), \\
u=-\frac{k}{\mu}\left(\frac{\partial p}{\partial x}-\rho g \sin \alpha\right), \\
w=-\frac{k}{\mu}\left(\frac{\partial p}{\partial z}+\rho g \cos \alpha\right),
\end{array}
$$

where $\rho$ is the groundwater density, $g$ is the gravitational acceleration constant, $k$ is the ground permeability and $\mu$ is the viscosity. In the conservation of mass equation (1), we have a source/sink term $s(x, t)$ which represents the rate at which fresh water is supplied to/extracted from the aquifer-this will be described in more detail later. At the water table level $z=h(x, t)$, depicted as the blue curve in Figure 3, we have the following kinematic and dynamic boundary conditions

$$
\begin{aligned}
& w=\frac{\partial h}{\partial t}+u \frac{\partial h}{\partial x}, \quad \text { on } z=h(x, t), \\
& p=p_{a}, \quad \text { on } z=h(x, t),
\end{aligned}
$$

where $p_{a}$ is the atmospheric pressure. At the bedrock $z=0$, since no water goes through there, we have the impermeability condition

$$
w=0 .
$$

Upstream of the aquifer, at $x=0$, there is a constant source of water from the dam

$$
\int_{0}^{h(0, t)} u(0, t) d z=\frac{Q}{\ell}
$$


where $\ell$ is the typical dam width. Downstream of the aquifer at $x=L / \cos \alpha$, and the water table height must be at sea level, that is

$$
h(X, t)=H_{b} .
$$

Now, we non-dimensionalise all variables using the scalings 1

$$
\begin{gathered}
x=L \hat{x}, \quad z=H \hat{z}, \quad t=\frac{L^{2}}{K H} \hat{t}, \quad p=\rho g H \hat{p}, \quad u=\frac{K H}{L} \hat{u}, \\
w=\frac{K H^{2}}{L^{2}} \hat{w}, \quad s=\frac{K H}{L^{2}} \hat{s}, \quad h=H \hat{h},
\end{gathered}
$$

where $K=\frac{k \rho g}{\mu}$ is the hydraulic conductivity. Since the aquifer is long and thin, we can make the approximation

$$
\epsilon=\frac{H}{L}=\tan \alpha \approx \alpha \ll 1,
$$

Now equations (11)-(3) become

$$
\begin{array}{r}
\frac{\partial \hat{u}}{\partial \hat{x}}+\frac{\partial \hat{w}}{\partial \hat{z}}=\hat{s}, \\
\hat{u}=1-\frac{\partial \hat{p}}{\partial \hat{x}}, \\
\epsilon^{2} \hat{w}=-1-\frac{\partial \hat{p}}{\partial \hat{z}} .
\end{array}
$$

Taking the limit of small $\epsilon$, and integrating (13) across the water table $0 \leq z \leq h$, as well as using boundary conditions (4), (5) and (6), we get the following equation for the (non-dimensional) water table $h$ :

$$
\frac{\partial \hat{h}}{\partial \hat{t}}+\frac{\partial}{\partial \hat{x}}\left(\hat{h}\left(1-\frac{\partial \hat{h}}{\partial \hat{x}}\right)\right)=\hat{S}
$$

where $\hat{S}=\hat{s} \hat{h}$. Boundary conditions from equations (7) and (8) become

$$
\begin{aligned}
\hat{h}\left(1-\frac{\partial \hat{h}}{\partial \hat{x}}\right) & =q, \quad \text { at } \quad \hat{x}=0, \\
\hat{h} & =\tilde{H}, \quad \text { at } \quad \hat{x}=1,
\end{aligned}
$$

where we have introduced the non-dimensional constants $q=\frac{Q L}{K H^{2} \ell}$ and $\tilde{H}=\frac{H_{b}}{H}$. Equation (14), together with (15), (16) and some initial condition, can be solved for the water table height, provided we know the source/sink term.

Note that in non-dimensional coordinates, the velocity in the $\hat{x}$ direction is given by

$$
\hat{u}=1-\frac{\partial \hat{h}}{\partial \hat{x}}
$$

\footnotetext{
${ }^{1}$ Note that in general the angle $\alpha$ is unrelated to the thin and long geometry of the aquifer. In such cases one can still define an aspect ratio for the aquifer, which will be a small parameter, but proceed with arbitrary angles. Here we have small aspect ratio and a small sloping angle.
} 
Hence, even though we have not looked at seawater intrusion in the above model, a very useful conclusion can be drawn here: if the gradient of the water table $h_{x}$ is greater than one at $\hat{x}=1(\mathrm{sea})$, then we expect seawater intrusion at the water table height. Likewise, if $h_{x}$ is less than one, we expect freshwater to flow outwards into the sea. Seawater intrusion is studied with a more detailed model later on.

In Figure $4(x, T)$ is plotted for $T=5$. We see that the solution has reached a steady state. The green curve is the water table when $S=0$ and the red curve is the water table for $S<0$, as shown in Fig. 4 with a blue colour. In Fig. 4 we also plot the line $h=x$ at $x=1$ (sea), which shows that both the green and the red curve have $h_{x}<1 \Longrightarrow u=1-h_{x}>0$ at the boundary with the sea and there is little risk of seawater intrusion.

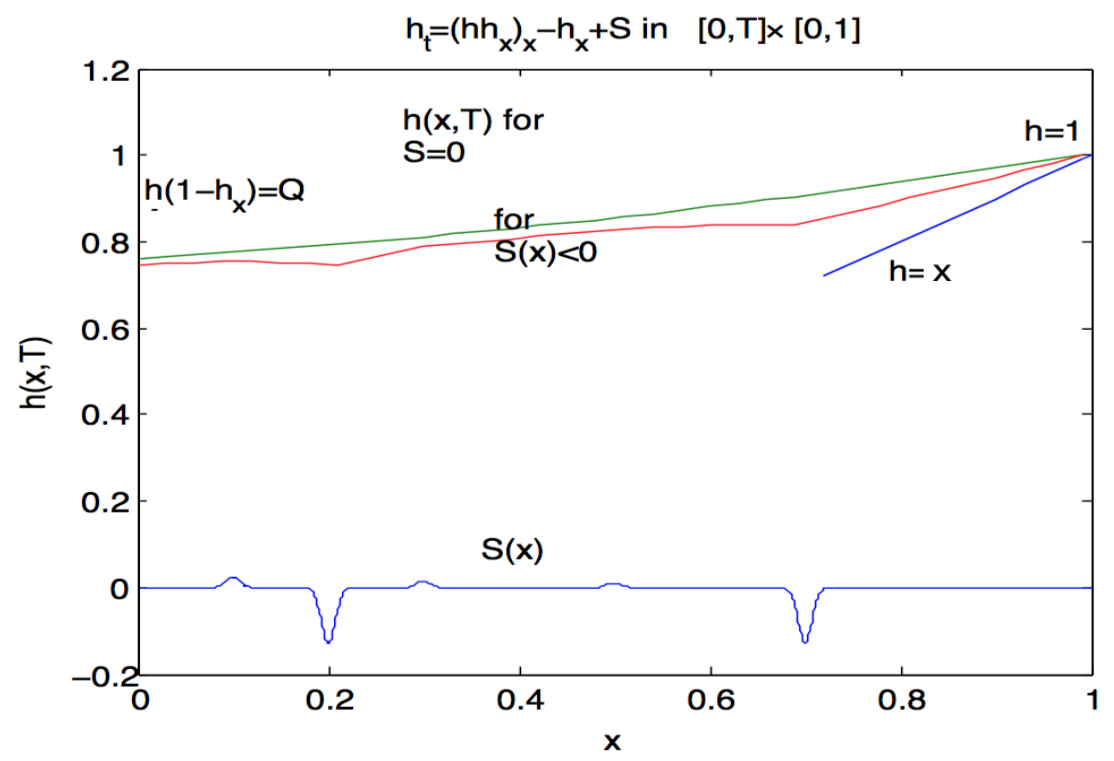

Figure 4: The water table for $T=5, h(x, 5)$, drawn when $S$ is zero (green line) and for non-zero $S$ (red line). The chosen form of the non-zero $S$ is also plotted with a blue line ( 3 sources, 2 sinks). We also plot the line $h=x$ near $x=1$, i.e. $h_{x}=1$ there to emphasise that $h_{x}<1 \Longrightarrow u=1-h_{x}>0$ for both the red and the green line, at the boundary with the sea. This indicates that the fresh water flows outwards and there is little risk of seawater intrusion.

\section{$3.2 \quad$ Optimal Recharge Strategy}

In this section we use the mathematical model given by Equations (14)-(16) to investigate how to control the aquifer water table by changing the recharge process in order to waste as little water as possible.

Currently, WDD uses four recharge points to recharge the aquifer and extracts water from 19 extraction points. The overall flow rate of extraction and recharge shall be denoted by $m^{+}$and $m^{-}$, respectively. We assume that the recharge sources are point sources and we approximate them with rectangular sources (see Fig. 5) at positions $x / L=b_{i}$ and area $A_{i}$, for $i=1,2,3,4$, and that the sinks are bundled together into 
a distributed sink extending from $x / L=a_{1}$ and $x / L=a_{2}$, over a width $d$ (see Fig. 5).

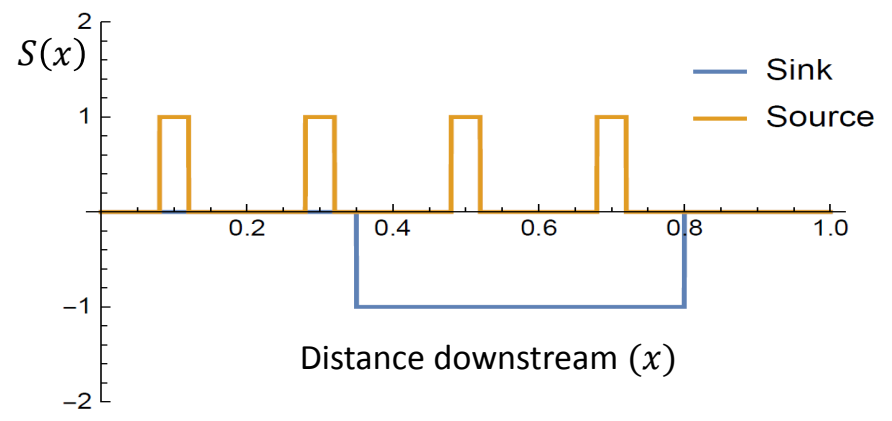

Figure 5: The four recharge points approximated as rectangular sources and the 19 extraction points bundled together into an extended, uniform, sink.

Therefore $S(x, t)$ mathematically is expressed as

$$
S(x)=M^{-} \Theta\left(x-a_{1}\right) \Theta\left(a_{2}-x\right)+\sum_{i=1}^{4} M_{i}^{+} \delta\left(x-b_{i}\right),
$$

where $\Theta$ is the Heaviside function, $\delta$ is the Dirac delta function and the strength of the distribution $M^{-}=\frac{m^{-} L}{d H^{2} K\left(a_{2}-a_{1}\right)}$ and $M_{i}^{+}=\frac{m_{i}^{+} L^{2}}{A_{i} H^{2} K}$ are the non-dimensional flow rates.

The WDD have control over how much water they inject into the aquifer. They want to recharge with enough water so that the water table does not sink below a critical level $h(x, t)=f(x)$ (which has been determined empirically) but they do not want $h(x, t)$ to be much higher than the minimum acceptable line since this would waste water unnecessarily. Mathematically this can be cast as an optimisation problem in which we aim to minimise the discrepancy between $\hat{h}$ and $f(x)$ by choosing optimal recharge rates $M_{i}^{+}$. In mathematical terms, this is equivalent to

$$
\min _{M_{i}^{+} \in\left[0, M_{\text {max }}\right]}|h-f|,
$$

subject to the constraints that $h \geq f$, and that $h$ must satisfy equations (14), (15) and (16). We also shall assume that the system is at steady state, so there is no need for an initial condition.

In Figure 6, for four scenarios of interest, we plot the solution to the optimal control problem (19); the optimal recharge rates and the corresponding water table. We choose as minimum and maximum values of the dam flow rate measured values 


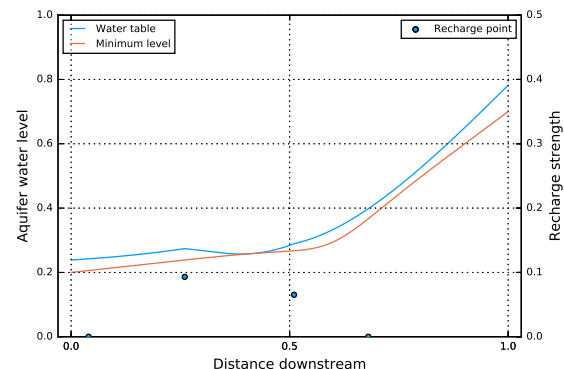

(a) $q_{\max }, M_{\min }^{-}$

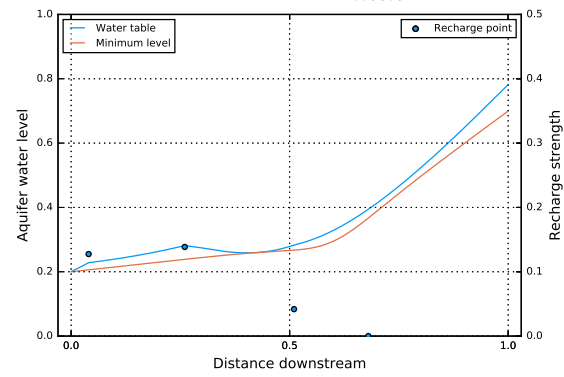

(c) $q_{\min }, M_{\min }^{-}$

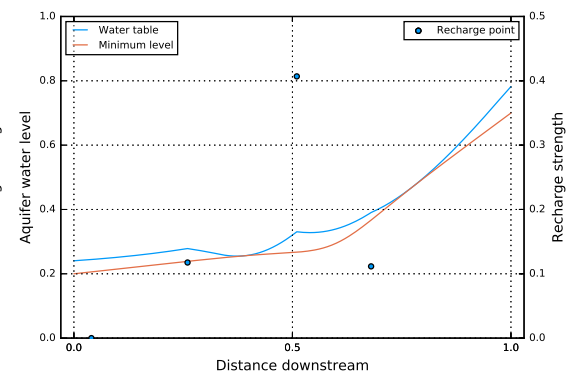

(b) $q_{\max }, M_{\max }^{-}$

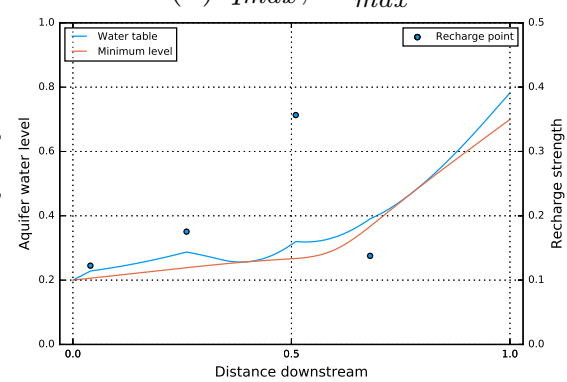

(d) $q_{\min }, M_{\max }^{-}$

Figure 6: Solution of the optimal control problem displayed together with the minimum water table (red curve) and recharge quantities $M_{i}^{+}$. The optimal recharge rates for each scenario are denoted by dots and the corresponding water table with blue. (a) Maximum dam seepage $q$ and minimum extraction rate $M^{-}$, giving a value of $\eta=3.6$. (b) Maximum dam seepage and maximum extraction rate, giving a value of $\eta=1.6$. (c) Minimum dam seepage and minimum extraction rate, giving a value of $\eta=2.0$. (d) Minimum dam seepage $q$ and maximum extraction rate $M^{-}$, giving a value of $\eta=1.9$.

supplied by the WDD as $Q_{\min }=2000 \mathrm{~m}^{3} /$ day and $Q_{\max }=7000 \mathrm{~m}^{3} /$ day. For the extraction rate, we also choose a small and a large value to correspond respectively to small and large water demand. The chosen values of $M^{-}=1$ and $M^{-}=2$ correspond to an extraction rate of approximately $20000 \mathrm{~m}^{3} /$ day and $40000 \mathrm{~m}^{3} /$ day. We also define the ratio of the rate of extraction to recharge as

$$
\eta=\frac{M^{-}\left(a_{2}-a_{1}\right)}{\sum_{i=1}^{4} M^{+}}
$$

which we evaluate for each of the four scenarios above. In each scenario $\eta>1$, and so the optimal strategy allows more water to be extracted than injected. This is less wasteful than the current recharge strategy, in which the recharge water quantity is approximately the same to the extracted water quantity. Also, two immediate conclusions can be drawn from Figure 6: (a) smaller dam seepage flow rates require larger injection rates upstream, (b) and larger extraction rates require larger injection rates downstream. A list of the other parameter values used in this analysis is given in Table 1 . 


\begin{tabular}{|c|c|c|}
\hline Constant & Value & Units \\
\hline$Q_{\min }$ & 2000 & $\mathrm{~m}^{3} /$ day \\
$Q_{\max }$ & 7000 & $\mathrm{~m}^{3} /$ day \\
$H$ & 78 & $\mathrm{~m}$ \\
$H_{b}$ & 61 & $\mathrm{~m}$ \\
$L$ & 5700 & $\mathrm{~m}$ \\
$K$ & 150 & $\mathrm{~m} /$ day \\
$\ell$ & 200 & $\mathrm{~m}$ \\
$d$ & 200 & $\mathrm{~m}$ \\
$a_{1}$ & 0.33 & \\
$a_{2}$ & 0.96 & \\
$b_{1}$ & 0.04 & \\
$b_{2}$ & 0.26 & \\
$b_{3}$ & 0.51 & \\
$b_{4}$ & 0.68 & \\
\hline
\end{tabular}

Table 1: List of parameter values.

\subsection{Conclusions}

In this section we have presented a simple mathematical model, based on Darcy flow, which can be used to predict aquifer flow for a chosen recharge and extraction protocol. The velocity of the flow and the water table level can be easily obtained using a simple numerical scheme. We have also designed an optimisation method which we used to determine the minimum flow rate at the recharge points that ensure that, at steady state, the water table will be above the minimum acceptable water level in the aquifer. The model can be generalised to incorporate variations in the width and the base of the aquifer and to include more sources and sinks, as required. Note that the ingress of the seawater has not been considered explicitly here but the boundary condition (16) at the aquifer-sea boundary allows us to conclude that there will be no significant risk of sea intrusion in the scenarios we have examined. More details can be found in [1].

\section{Model including seawater intrusion, using the open code SUTRASuite}

In this section we use the open source code SUTRASuite to investigate through numerical simulations several extraction/recharge scenarios for the aquifer based on mathematical models of saturated-unsaturated groundwater flows, now including seawater intrusion. The mathematical model we set up captures all features of interest when managing the Germasogeia aquifer:

- the groundwater flow induced by different recharge sources and extraction wells

- the water table level and how it varies for different recharge/extraction scenarios 
- the seawater intrusion effects for different recharge/extraction scenarios. For this we allow the groundwater density to be variable due to the presence of saltwater.

\subsection{The mathematical model}

In this section we briefly describe the mathematical model for the flow in the aquifer which allows for the possibility of seawater intrusion. This model is implemented using SUTRASuite below. Note that a more extensive description of a similar (but not identical) mathematical model can be found in section 5, based on computational fluid dynamics.

The unknown quantities to be found are the fluid pressure $p=p(x, t)$ and the salt mass fraction $m_{\text {salt }}=m_{\text {salt }}(x, t)$. Some physical quantities vary with respect to these functions and they are given by chosen state equations e.g. for the fluid density $\rho=\rho\left(m_{\text {salt }}\right)$ and for the water saturation $S_{w}=S_{w}(p)=S_{w}(p(x, t))$. The water saturation function $S_{w}$ implicitly describes the position of the water table that itself is an abstract interface between the fully saturated zone of aquifer, where $S_{w} \equiv 1, p \geq 0$ with no air presence in the pores, and between the partially saturated zone, i.e. $S_{w}<1, p<0$ with a presence of air in the pores.

The groundwater flow is characterized by the so-called Darcy velocity,

$$
\mathbf{q}=-\frac{k_{r} k}{\mu}(\nabla p-\rho \mathbf{g})
$$

where $k=k(x)$ is the permeability (a tensor in general), $\mu$ is the fluid viscosity (in general $\left.\mu=\mu\left(m_{\text {salt }}\right)\right)$ and $\mathbf{g}$ is the gravity vector. The function $k_{r}=k_{r}\left(S_{w}(p)\right)$ describes the relative permeability such that $k_{r}(1)=1$ and $k_{r}\left(S_{w}\right)<1$ for $S_{w}<1$. Note that so-called average fluid velocity $\mathbf{u}$ with respect to the stationary solid matrix of porous media [4] is given by $\mathbf{u}=\mathbf{q} /\left(\varepsilon S_{w}\right)$ where $\varepsilon$ denotes the porosity of aquifer.

The model is a system of two partial differential equations:

$$
\begin{array}{r}
\frac{\partial\left(\varepsilon S_{w} \rho\right)}{\partial t}+\nabla \cdot(\rho \mathbf{q})=Q_{\text {in }}+Q_{\text {out }}, \\
\frac{\partial\left(\varepsilon S_{w} \rho m_{\text {salt }}\right)}{\partial t}+\nabla \cdot\left(\rho m_{\text {salt }} \mathbf{q}-\varepsilon S_{w} \rho D \nabla m_{\text {salt }}\right)=m_{\text {salt }} Q_{\text {out }} .
\end{array}
$$

$Q_{\text {in }}$ and $Q_{\text {out }}$ denote the fluid mass sources and sinks respectively, and $D=D(\mathbf{q})$ describes the diffusion and dispersion tensor [4]. We note that we consider the sources $Q_{i n}$ to represent recharge with only fresh water.

A more detailed description can be found in the SUTRASuite documentation [4] where even more general settings are considered like e.g. a solute or heat transport modelling.

Numerical modelling of groundwater flow has a very long tradition in scientific and engineering studies, see for example the webpage of the U.S. Geological Survey, water.usgs.gov/software/lists/groundwater, where several free software tools are available. See also [2]. For our purposes the software SutraSuite appears as the most suitable for several reasons. First of all, a user-friendly graphical interface is 


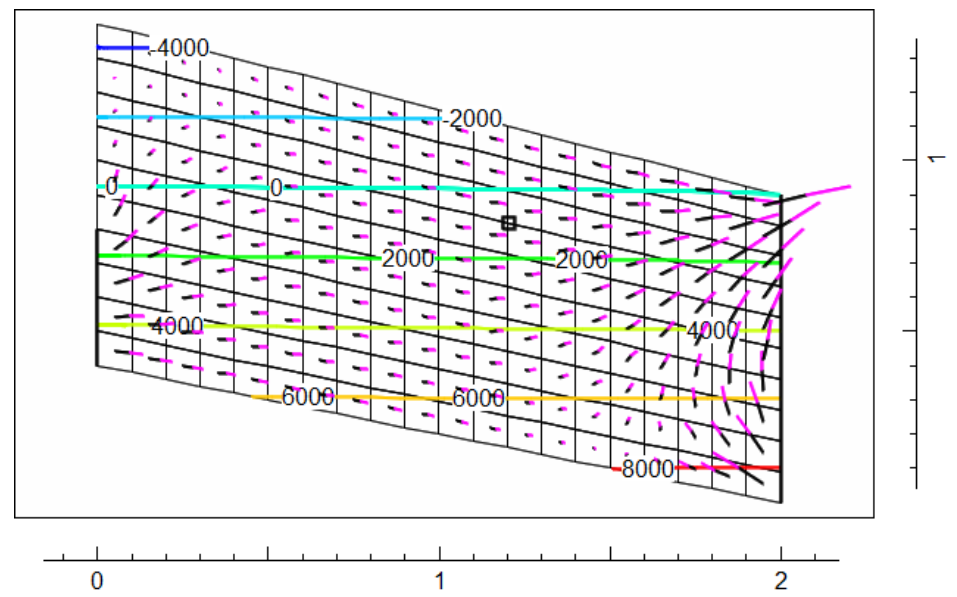

Figure 7: Initial settings of the modified Henry's problem. The contour lines represent pressure values with the zero value representing the position of the water table. The arrows represent the groundwater flow. The left edge of the rectangular domain is taken as the boundary between the dam and the aquifer with prescribed recharge rates at the lower part. The right edge of the rectangular domain is taken as the boundary between the sea and the aquifer with prescribed and fixed hydrostatic pressure. The aquifer contains only fresh water initially. A very coarse (unrealistic) computational mesh is used represented by $20 \times 10$ elements

available called ModelMuse which can be used to create $2 \mathrm{D} / 3 \mathrm{D}$ computational domains and for choosing the control parameters of the simulation. The SUTRA code (the main part of SutraSuite) can numerically solve mathematical models describing all features of interest for the Germasogeia aquifer. In particular, it can cope with transient simulations of saturated and unsaturated groundwater flow which involve a moving water table as an interface between fully saturated porous media (no air in pores) and partially saturated porous media (some air in pores).

\subsection{Modified Henry's problem of seawater intrusion}

To investigate seawater intrusion we start from running a well-known example of seawater intrusion, the so-called "Henry's problem" [3, 2, 4]. This example contains features that are useful for the numerical simulations of the Germasogeia aquifer-see Figure 7. We modify the problem so that the original rectangular domain is now inclined, see Figure 6, and also the recharge on the left edge of the domain (dam) is defined only in the lower part and not on the whole edge as in the original settings (which seems to be the case with the Germasogeia dam seepage). Additionally, the pressure is fixed on the right end of domain such that the "hydrostatic" initial pressure defines an unsaturated zone in the domain where nonpositive values of pressure can be observed. Other data are used as described in the user manual [4] for Henry's problem or with the default values of SUTRA code. The situation in Figure 7 represents the initial condition for the simulations, allowing for the seawater to enter the aquifer. The most important question related to Henry's 


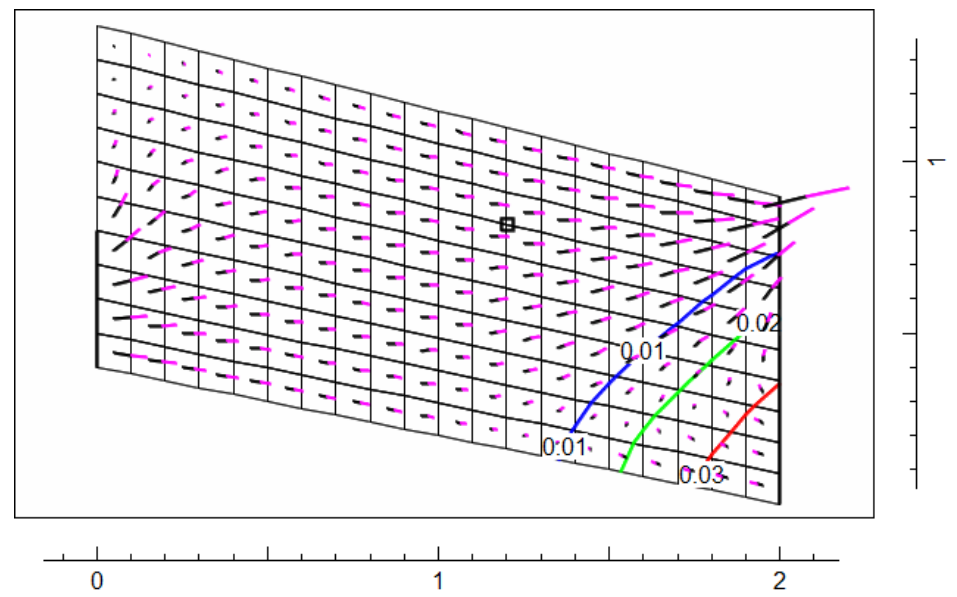

Figure 8: Steady state situation for the transient simulation from initial settings as given in Figure 7. The extraction is represented with a single point sink, represented by a square. The contour lines represent now the mass fractions of salt water, so a seawater intrusion occurs in this example.

problem is in which form the spreading of the seawater will equilibrate. The results of the simulation, left to run for a long enough time, is depicted in Figure 8 where the contour lines of the salt mass fraction are plotted. This steady solution for the modified Henry's problem is analogous to the solution of the original problem and it will be used to compare it with other simulations later on. Before running several illustrative examples with different recharge and extraction scenarios to see their influence to the groundwater flow and the salt mass fraction transport of the modified Henry's problem, we comment which data is needed for these simulations. We want to determine two unknowns - the fluid pressure and the salt mass fraction. Other physical quantities such as the fluid density or the flow velocities are derived from these two quantities and other given physical parameters. The salt mass fraction in the domain must be given by users at $t=0$, and the initial pressure is computed by SUTRA for data given by the WDD. Both unknown quantities must be prescribed on the boundaries (dam and sea respectively) during the simulation time. In the following simulations we additionally incorporate one extraction sink (which bundles together the 19 extraction points) and one recharge source. A description of the employed mathematical model has been given in Section 4.1.

In the first example we consider we introduce a single extraction point. The user can easily define the locations of the sources and sinks, and the corresponding rates of extraction and recharge using the graphical interface ModelMuse. In this example we find that a large extraction rate decreases the position of the water table (zero pressure level), see Figure 9, where (nonstationary) results are presented after some time starting the transient computations with the initial situation given in Figure 7 . Clearly, the water table height decreases significantly compared to that in Figure 7 . In the next example we choose a more realistic extraction rate. The result of such computation can be found in Figure 10 where the initial pressure is plotted together with the flow velocities. One can see in this Figure that the following three aspects 


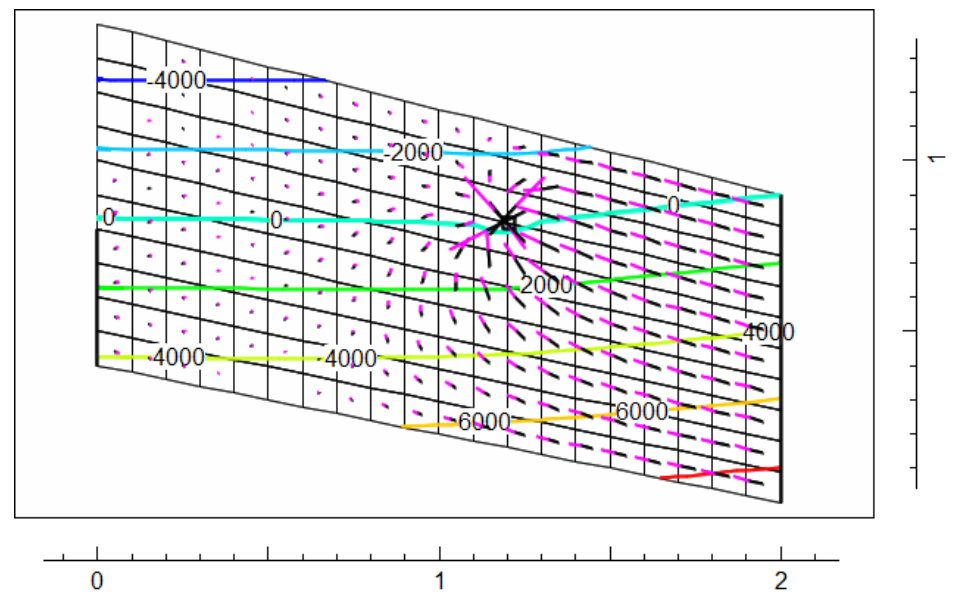

Figure 9: Simulation using the initial settings given in Figure 7, with an additional extraction point source (denoted as a small square in the domain) with a too large extraction rate. The contour lines represent the pressure. Clearly, a deformation of the water table (the zero pressure line) and large flow velocities from the right boundary (the sea) are observed.

influence the flow comparably: the recharge from the dam, the seawater intrusion and the extraction from the point sink-compare also with Figure 7. When comparing the results for a nonzero extraction rate in Figure 10 with the results for the zero extraction rate in Figure 6, one can clearly expect for transient simulations that a larger seawater intrusion must occur. This is confirmed by the results of transient simulation as presented in Figure 11 where the salt mass fraction contour lines are plotted after some time period and where the salty water reaches the vicinity of extraction well. Our final illustrative example is based on the addition of recharge on a part of the top edge of computational domain. The situation for these final settings is illustrated in Figure 12 where the rates of both external sources (the recharge) and the rate of sink (the extraction) are plotted.

The results of initial pressure computations and the resulting flow velocities are plotted in Figure 13. One can observe that the addition of recharge at the top of the domain can compensate the extraction in the sense that the seawater inflow on the right is not qualitatively different to the situation in Figure 7 with zero extraction. This is confirmed also by transient simulations for which a stationary situation could be reached, see Figure 14, where the seawater intrusion is comparable with the situation in Figure 8 .

Finally, we comment on the applicability of SUTRA to solve the challenges posed by the WDD. To perform the numerical simulations of different extraction and recharge scenarios for Germasogeia aquifer the following nontrivial tasks must be realised: (a) a more realistic description of the aquifer geometry must be used as done to some extent in the next section (b) Much finer computational grids must be used to obtain (almost) grid independent numerical solution. (c) The modelling of the unsaturated zone in the aquifer needs input data (see Section 4.1), that are not easy to find and should be obtained by some sort of model calibration. 


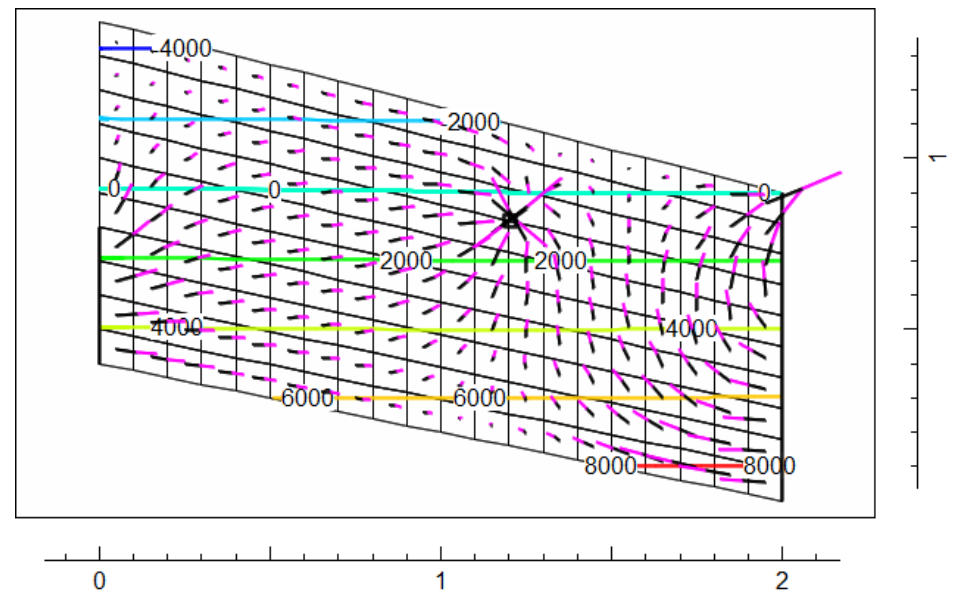

Figure 10: Initial pressure (the contour lines) and flow velocities for a more realistic extraction rate (singular sink). One can recognize the recharge from the dam on the left, the seawater inflow from the right and the extraction from the point sink.

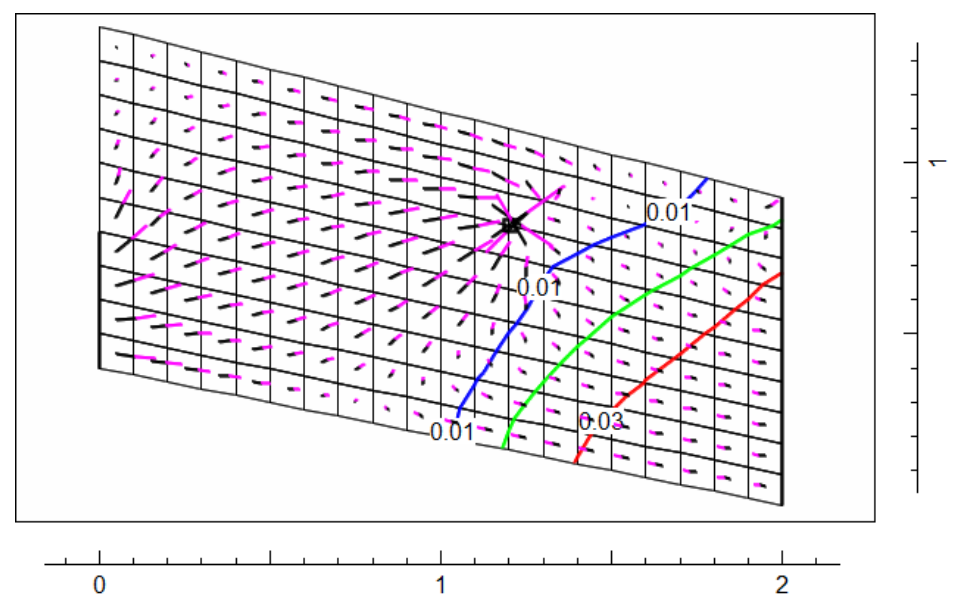

Figure 11: An illustration of transient simulations starting from the initial situation as given in Figure 10. The salt mass fraction contour lines and the flow velocities are plotted. Comparing this plot with Figure 8 in which the zero extraction rate is given one can clearly recognize that the seawater intrusion is too large and one can expect that the salt water enters the extraction well. 


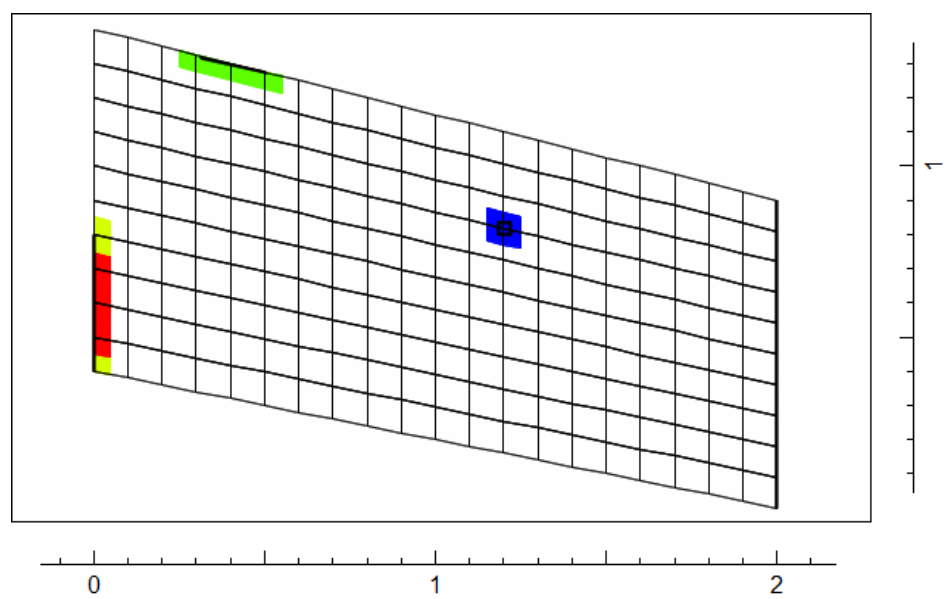

Figure 12: Recharge and extraction distributions. The blue colour represents the negative rate (the extraction) and the other colours represent the positive values (the recharge).

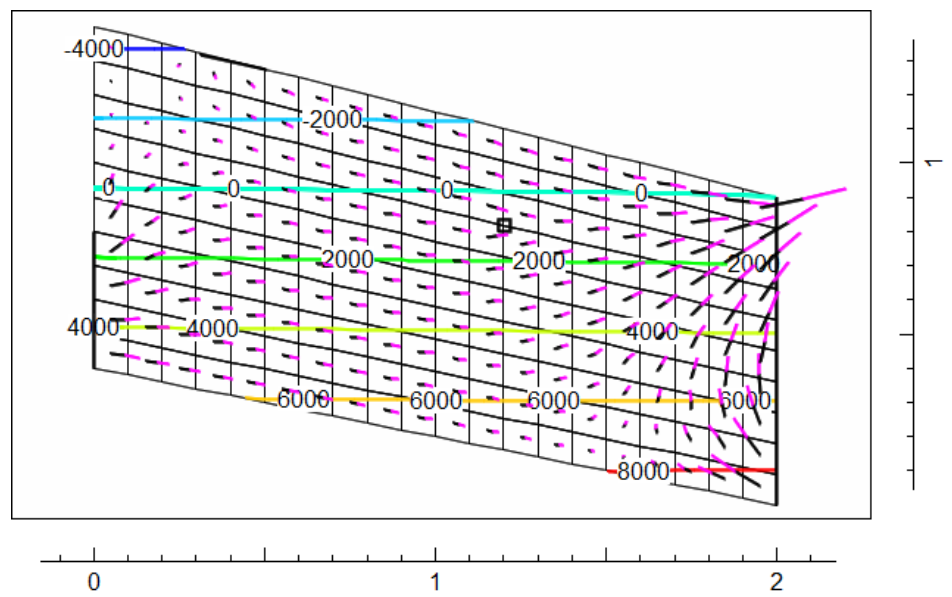

Figure 13: The initial pressure and flow velocities for the extraction and recharge rates as defined in Figure 12 . 


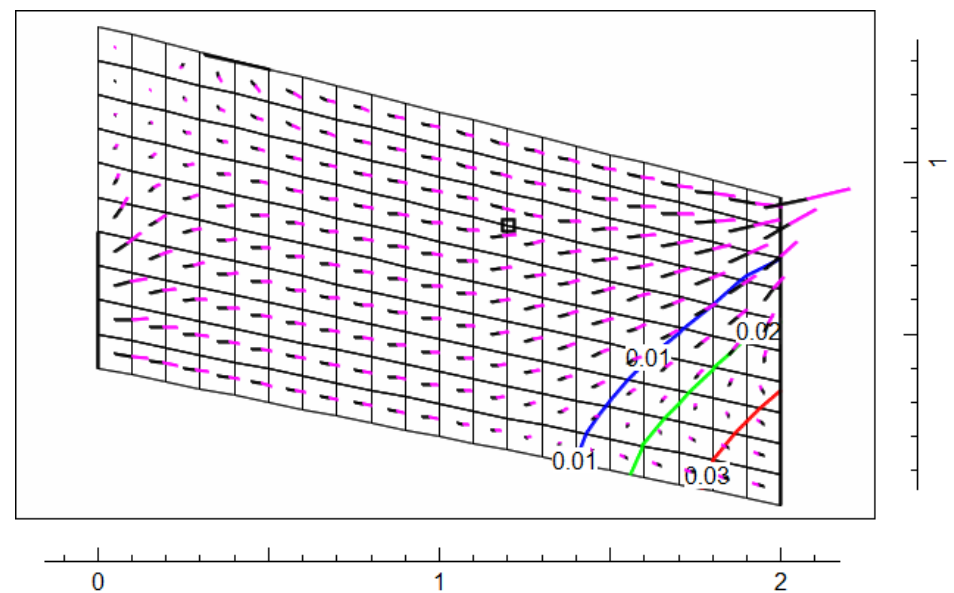

Figure 14: Stationary numerical results for the salt mass fraction (the contour lines) and the corresponding flow velocities (arrows) for the initial situation given by Figure 13 .

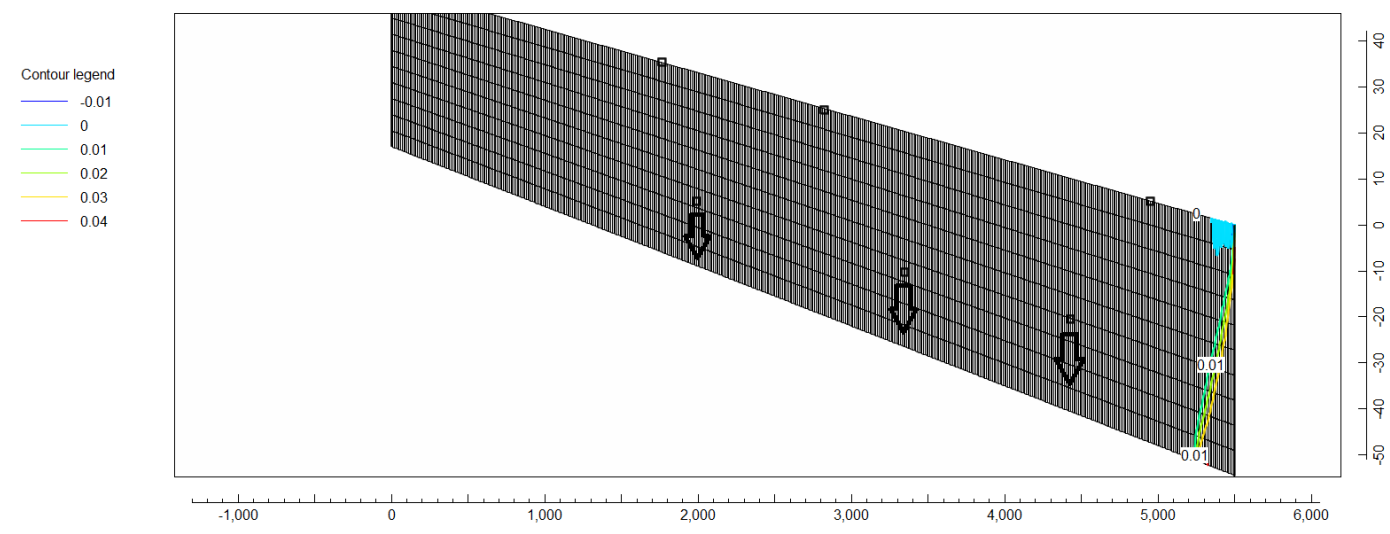

Figure 15: The two-dimensional aquifer geometry used in the SUTRA simulations investigating seawater intrusion.

\subsection{Mathematical model with seawater intrusion, using a more re- alistic aquifer geometry (in SUTRA)}

We now implement the more realistic two-dimensional approximation of the aquifer by considering a cross-section of the aquifer, as discussed in the Introduction and in relation to Fig. 1). For the simulations below we take the length $L=5.5 \mathrm{~km}$, the width at the dam equal to $35 \mathrm{~m}$ and width at the sea equal to $55 \mathrm{~m}$.

In this setup, we then introduce the 4 recharge points, denoted with squares on the top of the domain in Fig. 15. Several extraction points are incorporated in the model, having a net out-flux, equivalent to that of the Germasogeia aquifer. The extraction points are depicted with arrows in Fig. 15. We carry out numerical experiments, in order to study how the recharge rates affect sea intrusion. First, we consider the recharge rates that correspond to i.e $1000 \mathrm{~m}^{3} /$ day, $6000 \mathrm{~m}^{3} /$ day, 4000 $\mathrm{m}^{3} /$ day, $500 \mathrm{~m}^{3} /$ day. The sea intrusion area can be seen in Fig. 16. 
When lowering the recharge rate at the fourth point (i.e., the one that is nearest to the sea), the sea intrusion is larger. We simulate the process for a time range of about 3 days and for this period of time, the sea water gets into the aquifer for about $50 \mathrm{~m}$ more.

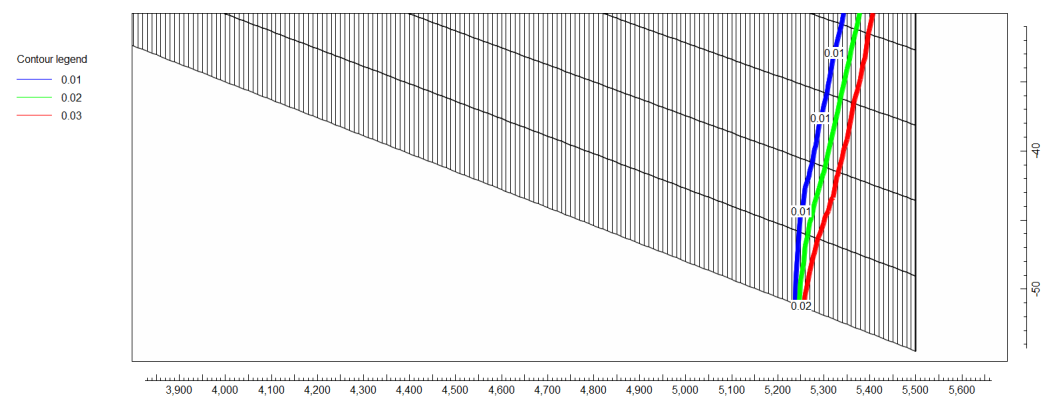

Figure 16: Seawater intrusion for the recharge rates of the Germasogeia aquifer.

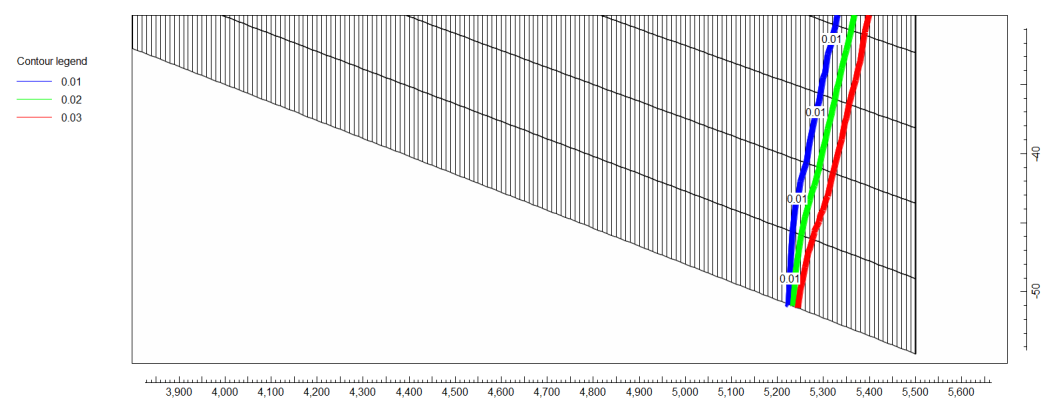

Figure 17: Seawater intrusion for a lower influx rate at the last recharge point.

Further work is necessary in order to simulate a complete 3D model of the aquifer including a detailed description of all the sources and sinks. Then, the inverse problem should be formulated and algorithms for its solution should be studied. I.e., one should consider what recharge rates are necessary, in order to ensure minimal sea water intrusion and enough water level in the aquifer.

\section{Modelling with seawater intrusion using ANSYS FLU- ENT}

In this section we present another modelling approach for the Germasogeia aquifer, described and implemented in commercial computational fluid dynamics software ANSYS Fluent [6].

\subsection{Model equations}

The incompressible fluid flow field $(\mathbf{u})$ in a porous medium (in case of a small Reynolds number $R e \ll 1$ ) is described by the Darcy-Brinkman formulation (as- 
suming Newtonian rheology)

$$
\rho \frac{\partial \mathbf{u}}{\partial t}=\nabla \cdot\left[-p \mathbf{I}+\frac{\mu}{\phi}\left(\nabla \mathbf{u}+(\nabla \mathbf{u})^{\mathbf{T}}\right)\right]-\frac{\mu}{k} \mathbf{u}+\rho \mathbf{g}
$$

where $\mu$ and $\rho$ are the fluid viscosity and density, $k$ and $\phi$ are the permeability and porosity of the medium, $\mathbf{g}$ is the gravity vector. In the limit of low permeability, typical in groundwater flows, the dimensionless Darcy number $D a=\frac{k}{L^{2}} \ll 1(L$ is the characteristic length scale). In such an instance, Eq. (24) is reduced to the conventional Darcy's relation

$$
\frac{k}{\gamma} \frac{\partial \mathbf{u}}{\partial t}+\mathbf{u}=-\frac{k}{\mu}(\nabla p-\rho \mathbf{g})
$$

where $\gamma=\mu / \rho$ is the dynamic viscosity of the fluid. The mass conservation equation reduces to the incompressibility condition

$$
\nabla \cdot \mathbf{u}=0
$$

Using the continuity equation (Eq. 26), the Darcy's relation Eq. (25) at steady state can be reduced to Laplace's equation for pressure as

$$
\nabla^{2} p=0
$$

Now as described in the problem introduction, the level of water in the porous bed is computed as the interface boundary between two fluids. The tracking of the interface(s) between the phases is accomplished by the solution of a continuity equation for the volume fraction of the phases. Ignoring interfacial mass transfer, the continuity equation for the $i^{t h}$ phase is

$$
\begin{aligned}
\frac{1}{\rho_{i}}\left[\frac{\partial}{\partial t}\left(\beta_{i} \rho_{i}\right)+\mathbf{u} \cdot \nabla \rho_{i} \beta_{i}\right] & =0 \\
\sum_{i=1}^{N} \beta_{i} & =1
\end{aligned}
$$

where, $N$ is the number of phases, $\beta_{i}$ is the phase fraction $\left(0<\beta_{i}<1\right)$ and $\rho_{i}$ is the density of the $i^{t h}$ phase. It may be noted here, that the bulk macroscopic properties $(\rho$ and $\mu)$ in Eqs. (24) and (25) follows from the simple mixing rule, $\rho($ or $\mu)=\sum_{i=1}^{\xi} \beta_{i} \rho_{i}\left(\right.$ or $\left.\mu_{i}\right)$. Only a single set of the momentum exchange equation, in the form of the Darcy's law is solved (Eqs. 25 and 26) to obtain $\mathbf{u}$, which is shared by all the phases $i$. In the present formulation, one of the phases is water while the other is air. So, based on Eq. (29), $\beta_{\text {water }}=1-\beta_{\text {air }}$ denotes the extent of partial saturation. Note that $\beta_{\text {water }}=1$ represents a completely saturated porous zone, while $\beta_{\text {air }}=1$ is completely unsaturated (dry). The sea water intrusion effect is modelled by allowing a variable water density, vayring as a function of the salt mass fraction $\left(m_{\text {salt }}\right)[10]$ as follows

$$
\rho_{\text {water }}(\text { in } g / c c)=1+0.695 m_{\text {salt }},
$$


where $0 \geq m_{\text {salt }} \geq \sim 0.1$. Typically, the mass fraction of salt in sea water ranges in between 4-6 wt\%. Similarly, the viscosity of water can be correlated with the $m_{\text {salt }}$ [10] as

$$
\mu_{\text {water }}(\text { in } c P)=1+0.09 m_{\text {salt }}+0.0093 m_{\text {salt }}^{2} .
$$

More complex (higher polynomial degree) correlations of the viscosity and density variations can be found in [12]. The species convective-diffusive model (considering the diluted solution approximation) is solved for the salt concentration,

$$
\frac{\partial m_{\text {salt }}}{\partial t}+\mathbf{u} \cdot \nabla m_{\text {salt }}=D_{\text {salt }} \nabla^{2} m_{\text {salt }},
$$

where $D_{\text {salt }}$ is the diffusivity of salt in the sea water.

\subsection{Problem description and boundary conditions}

In order to proceed with the simulations of the above model we implement the aquifer geometry as in Fig. 18. As described in the beginning, the horizontal length of the aquifer is around $5.5 \mathrm{~km}$, while the depth ranges from 35 (upstream, dam side) to $55 \mathrm{~m}$ (downstream, sea side), and since the width is much smaller than the length we continue with the two-dimensional approximation of the geometry. Also, the inclination angle is around 4 degrees. The permeability $(k)$ does vary significantly along the aquifer, so we assume an average value of $k$ for simplicity as in our previous models. In Fig. 18 the approximate locations of the recharge $\left(R_{1}\right)$ and extraction $\left(E_{1}\right)$ points are also shown. It may be noted that the recharge and extraction rates considered in the following simulations are the actual field values.

There are 19 working extraction borewells (each having a capacity of $1.08 \mathrm{~km}^{3} / d$ ) which extract water for urban distribution. In order to simplify the calculation, these 19 points are clubbed together into 6 points $\left(E_{1-6}\right)$ withdrawing equivalent total amount of water $\left(20.5 \mathrm{~km}^{3} / d\right)$. The extraction rate of $E_{1}$ equals to that 4 borewells, $E_{2,3}$ equals to that 2 borewells each, $E_{4,5}$ equals to that 3 borewells each and $E_{6}$ equals to that of 5 borewells. In practice, water is withdrawn from the top by the borewells which is mimicked (in the simulation) by considering sinks at the bottom of the aquifer for simplification. Obviously, this will affect the fluid patterns around the extraction regions (deviation from reality) but our objective to quantify the water table and sea intrusion effects will be unaffected.

The initial condition is considered to be the minimal water level just sufficient to prevent sea water intrusion. Mathematically this means that the red region in Fig. 18 has $\beta_{\text {water }}=1$ while everywhere else it is zero. The boundary condition at the bottom is no slip as well as no penetration $(\mathbf{u}=0)$ and $\beta_{\text {water }}=1$. While, at the top, it is the pressure condition (Eq. 33) and $\beta_{\text {water }}=0$. At the upstream wall (dam side), there is a constant influx equivalent to $5 \mathrm{k} \mathrm{m}^{3} / d$ and $\beta_{\text {water }}=1$ for the bottom half of the wall and the rest $\mathbf{u}=0$. The boundary condition on the sea side is the outflow condition for flow while Dirichlet condition for the phase variable $(\beta)$

$$
\begin{aligned}
{\left[-p \mathbf{I}+\mu\left(\nabla \mathbf{u}+(\nabla \mathbf{u})^{T}\right)\right] \cdot \mathbf{n} } & =-p_{0} \mathbf{n} \\
\beta_{\text {water }} & =1
\end{aligned}
$$




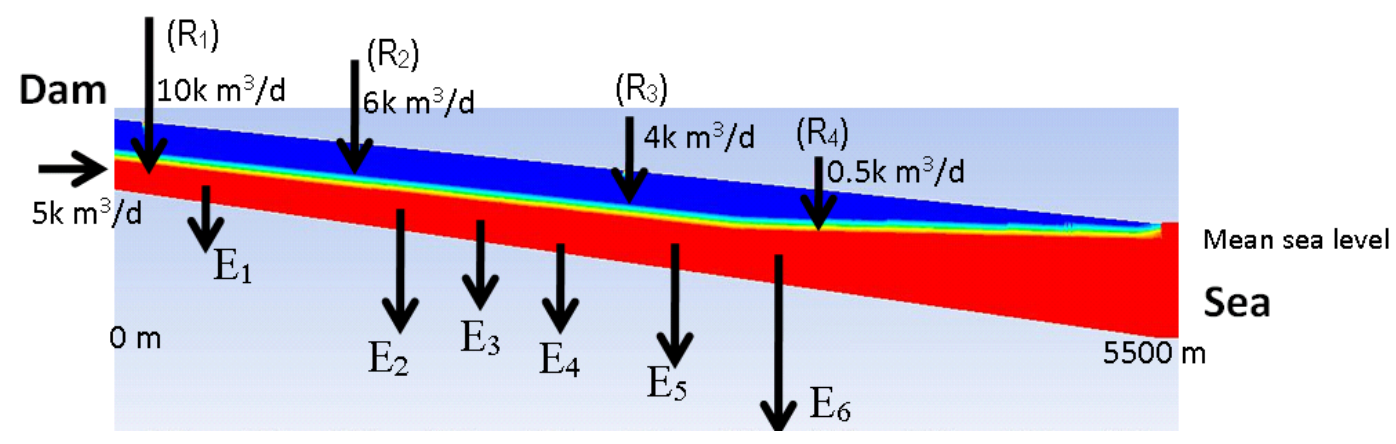

Figure 18: Description of the 2D model geometry with various extraction and recharge locations. Note $5 \mathrm{k} \mathrm{m}^{3} / \mathrm{d}$ equals to $5000 \mathrm{~m}^{3} / \mathrm{d}$ and not $5 \mathrm{~km}^{3} / \mathrm{d}$

where $p_{0}$ is the atmospheric pressure. For the species transport, the top and the bottom surface satisfy the no-flux condition

$$
-\mathbf{n} \cdot\left[\mathbf{u} m_{\text {salt }}-D_{\text {salt }} \nabla m_{\text {salt }}\right]=0
$$

Since there is no slip at the boundaries, Eq. (35) reduces to the Neumann condition $\mathbf{n} \cdot \nabla m_{\text {salt }}=0$. The concentration boundary condition at the sea side is fixed to the sea-water salinity $m_{\text {salt }}=0.05$ and at the upstream (dam side) is zero. Initially (at $t=0$ ), the region containing sea has $m_{\text {salt }}=0.05$ while everywhere else it is zero. The physical properties of the various fluid properties are considered for the standard values. The permeability $k$ is taken as $1.54 \times 10^{-10} \mathrm{~m}^{2}$ equivalent to the hydraulic conductivity of $130 \mathrm{~m} / \mathrm{d}$ (in geological units) 2 .

The system of equations are solved using FLUENT ${ }^{\circledR}$, which is based on a finite volume discretisation [6, 7]. The results of the simulations are presented below.

\subsection{Technical explanation about the algorithm used}

The momentum equation is discretised using the Quadratic Upstream Interpolation for Convective Kinematics (popularly known as QUICK) scheme [9], a higher-order differencing scheme based on the weighted average of second-order-upwind and central interpolations of the variable. One limitation of the shared-fields approximation is that in cases where large velocity differences exist between the phases, the accuracy of the velocities computed near the interface can be adversely affected. As such, the compressive interface capturing scheme for arbitrary meshes (CICSAM), based on the Ubbink's work [13], is a high-resolution differencing scheme. The CICSAM scheme is particularly suitable for flows with high ratios of viscosities between the phases. CICSAM is implemented in FLUENT as an explicit scheme and offers the advantage of producing an interface that is almost as sharp as the geometric reconstruction scheme [14]. This scheme is the most accurate, robust and is applicable for general unstructured meshes. Since the flow in the present case is dominated by body forces (gravity) rather than pressure gradients, a body-forced weighted

\footnotetext{
${ }^{2}$ Units note: The permeability $\left(\mathrm{m}^{2}\right)$ is generally calculated from the hydraulic conductivity $(\mathrm{m} / \mathrm{d})$, which is more commonly used in the hydrogeological community. For reference, $0.987 \times$ $10^{-12} \mathrm{~m}^{2}=1$ Darcy unit $=0.831 \mathrm{~m} / \mathrm{d}$.
} 
scheme with "pressure implicit with splitting of operators" (PISO) algorithm is used for pressure correction [8], which is an extension of the SIMPLE algorithm [11] used for solution of the momentum equation. The PISO algorithm shifts the repeated calculations required by SIMPLE and SIMPLEC inside the solution stage of the pressure-correction equation [8]. After one or more additional PISO loops, the corrected velocities satisfy the continuity and momentum equations more closely. The algorithm is slightly more CPU intensive, but dramatically reduces the number of iterations required for convergence, especially in transient problems. Simulations were initiated with very small time steps and were increased gradually for later times with no resultant spurious numerical oscillations in the solution.

The computational domain was meshed using unstructured hexagonal mesh elements (total of 27,053 mesh elements) with more refinement along the air-water interface (water level). Grid independence was tested at various dimensionless mesh sizes starting from 0.00013 to 0.0095 . It was observed that the mass continuity is conserved with an accuracy of $10^{-4}$ for dimensionless mesh sizes less than 0.0021 . Hence, the mesh size of 0.021 was considered adequate for the current numerical simulations. The region around the interface has a dimensionless minimum and maximum mesh size of 0.00045 to 0.0021 , with an average skewness of $0.78 \pm 0.13$. Similarly, the remaining geometry has minimum to maximum mesh size of 0.0013 0.0061 , with the average skewness of $0.73 \pm 0.19$.

\subsection{Results}

The evolution of the water level is shown in Fig. 19 for a period of 3 months. The actual aspect ratio of the geometry is scaled to 0.1 times the axial dimension for improving the visual appearance. The regions in red correspond to the saturated region $\left(\beta_{\text {water }}=1\right)$ while the blue regions are dry. The comparison of the recharge rates on the impact of the water table is illustrated in Fig. 20. The figure shows the inverse of the saturated zones (dry region is shown in the figure) for clear depiction of the difference in the water tables on the two different scenarios. As expected with all the recharges switched on, the dry region is less compared to the situation when the two intermediate recharge points are switched off. The result gives a quantitative understanding on how much the water level rises locally as well as globally due to the recharges. Further study on the variation of the recharge rate can show the measurable change in the water table as a function of the individual point recharge rates. This will provide the answer to the inverse problem as what are the best settings of the recharge rates to minimise sea water intrusion in this specific geological landscape. Due to switching off the two intermediate recharge points, sea water intrusion is more prominent. It must be emphasised that there is no special mathematical setting of the seawater-fresh water interface which evolves naturally as a part of the dynamic solution. Fig. 21 shows the seawater-freshwater interface. As anticipated, as seawater is heavier it is expected to settle towards the bottom if the aquifer with the freshwater on top. However, accounting for the effect of diffusion the seawater will slowly rise upstream, acting in the opposite direction of gravity. It might be interesting to find the shape of the interface as the seawater intrudes more upstream and the interface gets diffused due to the combined action of gravity 


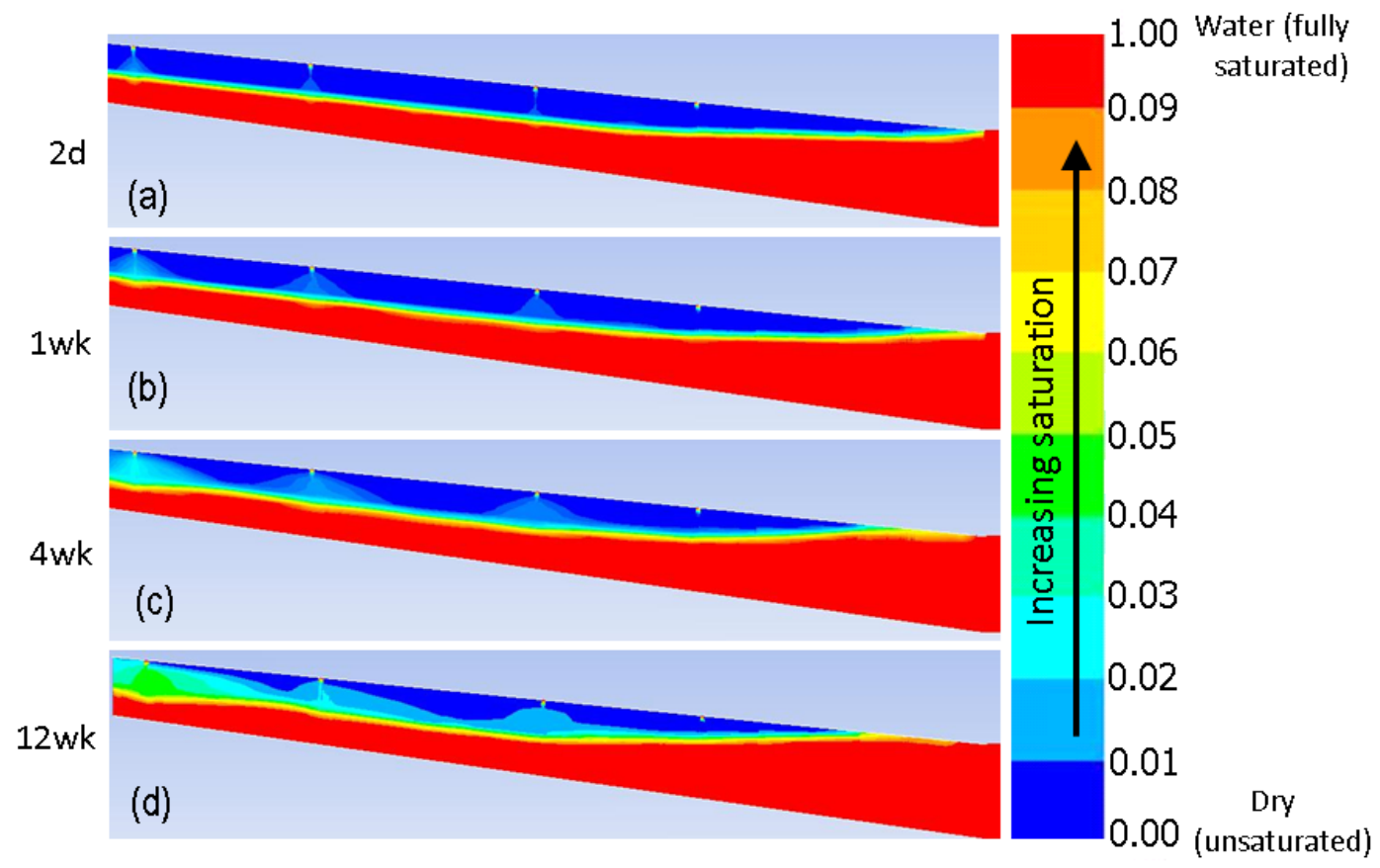

Figure 19: Visualisation of the water table landscape with time, switching on the recharge and extractions

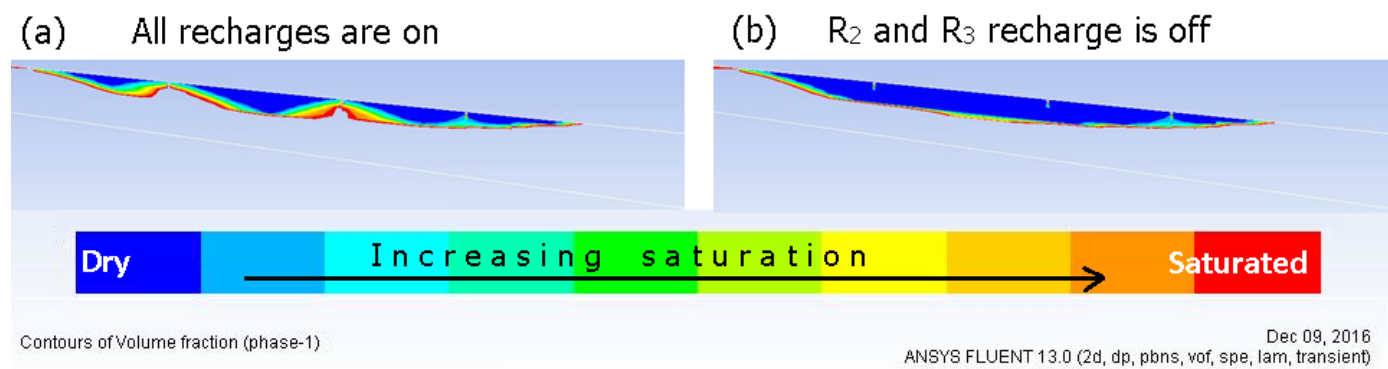

Figure 20: Comparison of two different cases with switching off the two intermediate recharges. The image shows the inverse of saturation (dry regions) 
(a) All recharges are on

(b) $R_{2}$ and $R_{3}$ recharge is off

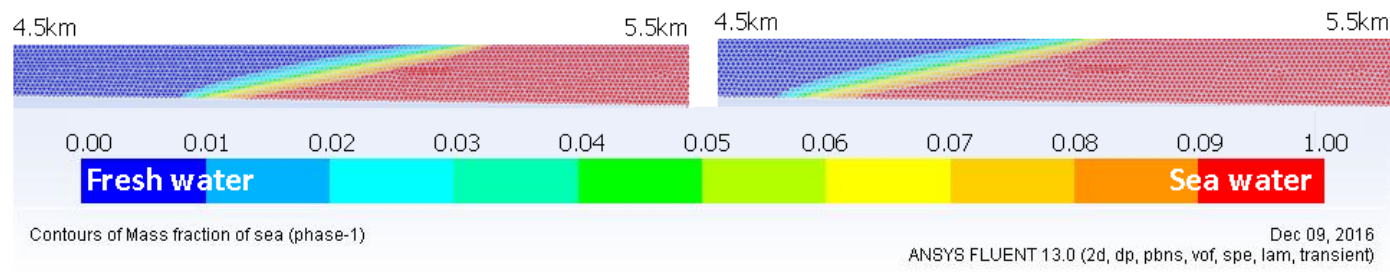

Figure 21: Effect on the sea water intrusion due to switching off two recharges

and diffusion. In the present scenario, when switching off the intermediate recharges, seawater intrudes around $120 \mathrm{~m}$ after 6 weeks compared to the scenario where all recharge points are on.

\section{Contaminant transport in the aquifer after accidental leakage}

\subsection{Description of the challenge: modelling contamination charac- teristics after an accidental leakage}

The aquifer runs through a busy urban area and hence the WDD would like to investigate the hypothetical scenario of the aquifer being contaminated accidentally by sewage, chemicals etc. To identify the most effective strategy to manage any hazard, it is necessary to predict the characteristics of the contamination; how fast it will spread and where. As the topography of the aquifer is not uniform and the recharge and extraction points are not equally spaced, it is highly probable that the location of the leakage will have a strong effect on the spreading of any contaminant. Also, the size of leakage and the duration of leakage are two important factors. Thus, for the safe management of the Germasogeia aquifer, it is important to develop a mathematical model that enables simulation of the spreading of the contamination in the aquifer for various hypothetical contamination scenarios. In this way the appropriate remedial measures can be taken by WDD in case of contamination.

The aquifer geometry is approximated as two-dimensional, as in the previous models, and we also assume again that the permeability $k$ is constant. In this case, the permeability was calculated from hydraulic conductivity values. The norm for unit conversions is $0.987 \times 10^{-12} \mathrm{~m}^{2}=1$ Darcy unit $=0.831 \mathrm{~m} / \mathrm{d}$. The aquifer geometry is shown in Fig. 22 where approximate locations of the recharge and extraction points are also shown. The recharge and extraction rates considered in this calculation are the actual field values. The 19 extraction points are bundled into groups of 6 as in the previous section. In practice, water is withdrawn from the top by the borewells which is represented in the simulations by considering sinks at the top of the saturated level in aquifer with a length of $1 m$, although in reality the effect of extraction affects a larger region. Although this assumption may lead a somewhat different flow pattern, the contaminant concentration profile will not be affected significantly. 


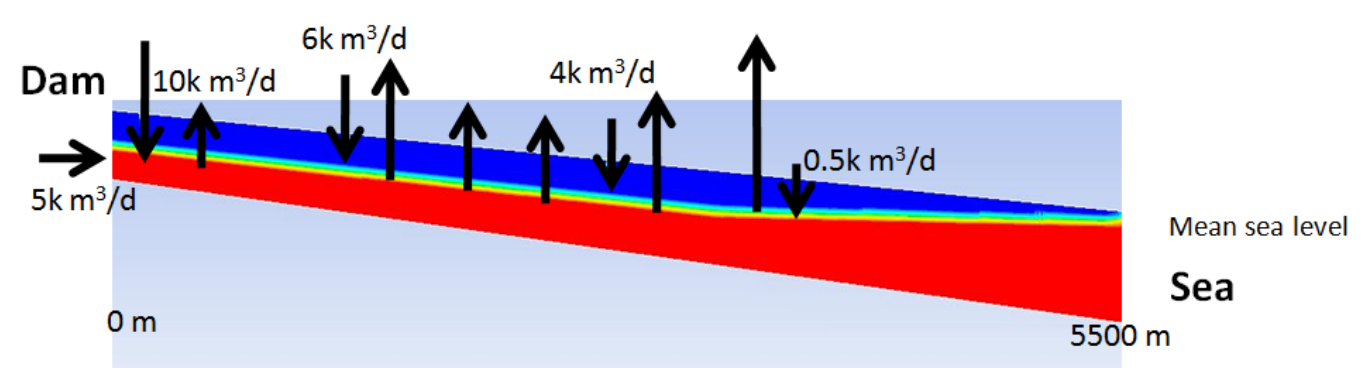

Figure 22: Schematic of the two-dimensional aquifer geometry implemented in the simulations; the 4 recharge points are denoted with downward looking arrows and 6 extraction sinks are denoted by upward looking arrows. Red is a fully saturated region and blue is a dry region.

\subsection{Mathematical model}

The modelling of contamination transport involves two parts: prediction of the aquifer water flow, and coupling this to the advection and diffusion of the contaminant. To model the concentration profile of the contaminant, the following advection-diffusion equation is used:

$$
\phi \frac{\partial c}{\partial t}+\nabla \cdot(-D \nabla c)+\mathbf{u} \cdot \nabla c=R_{c}+S_{c}
$$

Here, $\phi$ is the porosity of the aquifer, $c$ is the concentration of contaminant in $\mathrm{mol} / \mathrm{m}^{3}$, which is a function of space and time, $t$ is time in $d($ days $), \mathbf{u}$ is the water velocity (in $m / d$ ), obtained by solving Darcy's law in COMSOL, and $R_{c}$ and $S_{c}$ are the source and sink terms for the pollutant. The red region in Fig. 22 is fully saturated with water all the time and we expect that the effect of contamination will be most prominent in this region. For simplification, we solve for the concentration profile of the contaminant in the latter region. The boundary condition at the bottom of the aquifer is the no-slip condition $(\mathbf{u}=0)$ and the no-penetration condition. Also, at the top,there is no penetration of the flow through the edge of the boundary except at the recharge and extraction points. At the upstream wall (dam side), we implement a constant influx of water equivalent to $5 \mathrm{~km}^{3} / d$. The boundary condition at the sea is the open atmosphere gauge, $p=0$, with an assumption of negligible static water head throughout the depth of the aquifer.

Also, the concentration at the sea and at the dam is set to zero and initially (at $t=0$ ), the concentration is everywhere zero, except at the point of leakage. The physical properties of the various fluid properties are considered for the standard values. The permeability (constant $k$ ) is taken as $1.54 \times 10^{-10} \mathrm{~m}^{2}$, equivalent to a hydraulic conductivity of $130 \mathrm{~m} / \mathrm{d}$ (in geological units).

For the species transport, the dam side and the bottom surface satisfy the no-flux condition, defined by

$$
-\mathbf{n} \cdot(D \nabla c)=0 .
$$

The only inflow condition for the contaminant is at the leakage points (single or multiple). As there has never been any leakage in the past, no data are available 
from the WDD, and we assume that the concentration of the contaminant as 1 $\mathrm{mol} / \mathrm{m}^{3}$, a realistic enough value. The value of the diffusion coefficient depends on the nature of the solute (for example, the solute is mainly organic if the contaminant is domestic sewage), and on the nature of the porous medium. The diffusion constant typically varies in the order of $10^{-9}$ to $10^{-13} \mathrm{~m}^{2} / \mathrm{s}$ [17]. As our dispersion medium is water and the size of solid molecules can be safely assumed to be very small, we set the value of the diffusion coefficient to $5 \times 10^{-10} \mathrm{~m}^{2} / \mathrm{s}$ in the $x$ direction [17].The relation between effective diffusivity and diffusion constant is given by [18].

$$
D_{e f f}=D \phi \delta / \tau^{2}
$$

where $\delta$ is the pore constrictivity (value: 0.5 ) and $\tau$ is the tortuosity (value: 1.25 ), taken from [19]. Therefore, the value of effective diffusivity in soil is calculated to be $7 \times 10^{-10} \mathrm{~m}^{2} / \mathrm{s}$ in the $x$ direction $\left[15\right.$ and $1.4 \times 10^{-9} \mathrm{~m}^{2} / \mathrm{s}$, in the $y$-direction, i.e. double of that in the $x$-direction [16]. All the extraction points and the opening to the sea, are outflow points for the contaminant. Considering the large volume of sea water, it is safe to assume that the concentration of the contaminant at the boundary of the aquifer with the sea is zero.

\subsection{Simulation results}

The non-dimensional equations were set up in COMSOL Multiphysics 5.2 (commercial software which employs Finite Element Methods), and solved in the fullysaturated part of the aquifer. The top level of the saturated layer was taken to be the minimum acceptable water table as provided by the WDD. We examine two scenarios in which we take respectively the location of the leakage at $900 \mathrm{~m}$ (near the dam) and at $5000 \mathrm{~m}$ (near the sea); the leakage duration is taken the same in the two scenarios. Moderate variations in the precise location of the leakage do not have a significant effect on the spreading of the contaminant. The concentration profile of the contaminant after one week and after 26 weeks of leakage for case 1 is plotted in Figs. 23 and 24, respectively. (For better visualisation of the results, only the portion of the aquifer which contains contaminant (fully saturated region), is presented in the figures.) We observe that the leakage position has a very prominent effect on the spreading of the contaminant. For leakage near the dam rapid and wide spreading of the pollutant is expected. It is also evident in Fig.23, that the spreading of the contaminant is more significant in the $x$ direction. Whereas, the length of the spreading area is $1500-1600 \mathrm{~m}$ one week after the leakage, this does not get enhanced further as evident from Fig. 24. Alternatively, the concentration of sewage within this contaminated region gets enhanced with time.

Also, the concentration profiles of the contaminant one week and 26 weeks after of leakage for scenario 2, are shown in Figs. 25 and 26, respectively. Comparison of Figs. 25 and 26 reveals slower but continuous spreading of the contaminant in both the $x$ and the $y$ direction, for Scenario 2. One week after the leakage starts, the contaminated region is about $150 \mathrm{~m}$ long along the aquifer, whereas after 26 weeks, the length increases by only $400 \mathrm{~m}$. As the input velocity is much higher in Scenario 1, the advection of the contaminant is greater at that location. Advection is dominant over diffusion in Scenario 1, hence the spreading is more enhanced in the 


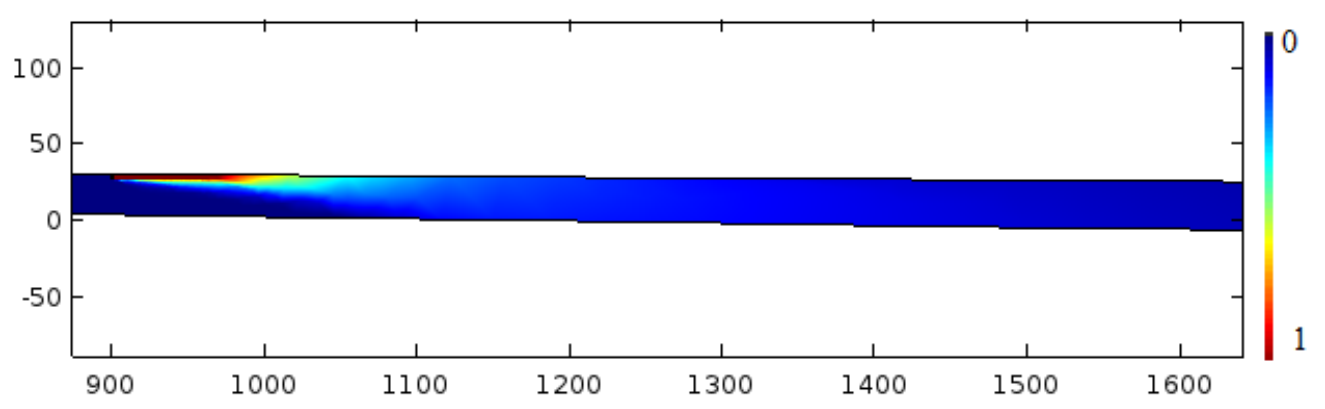

Figure 23: Concentration profile of the contaminant one week after the leakage started, at $900 \mathrm{~m}$ away from the dam.

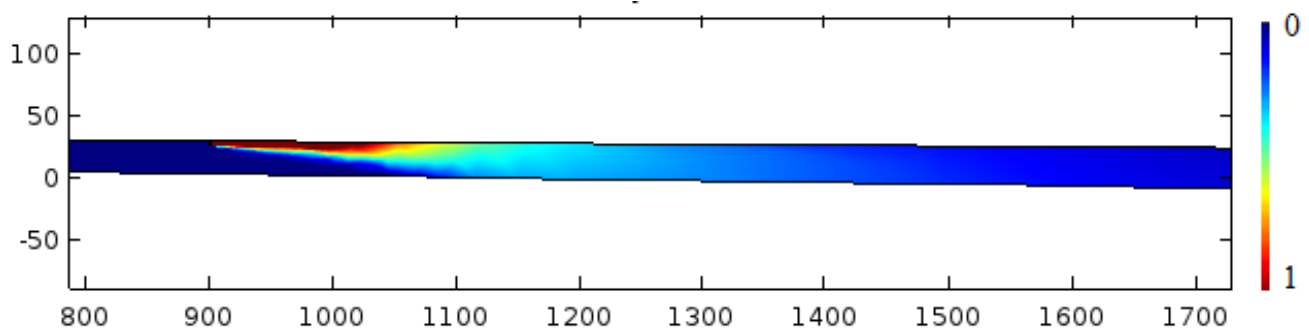

Figure 24: Concentration profile of the contaminant 26 weeks after the leakage started, at $900 \mathrm{~m}$ away from the dam.

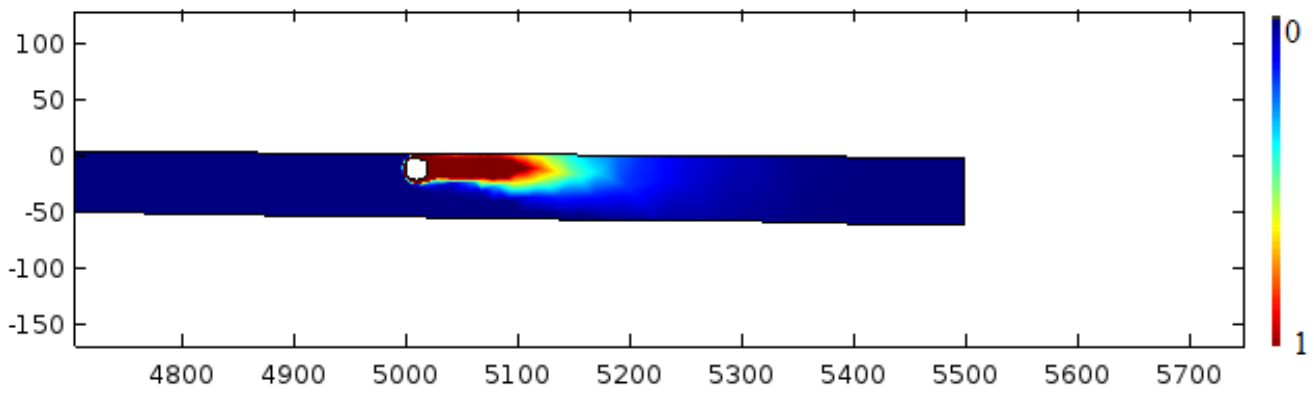

Figure 25: Concentration profile after one week of leakage, at $5000 \mathrm{~m}$ away from the dam (near the sea). 


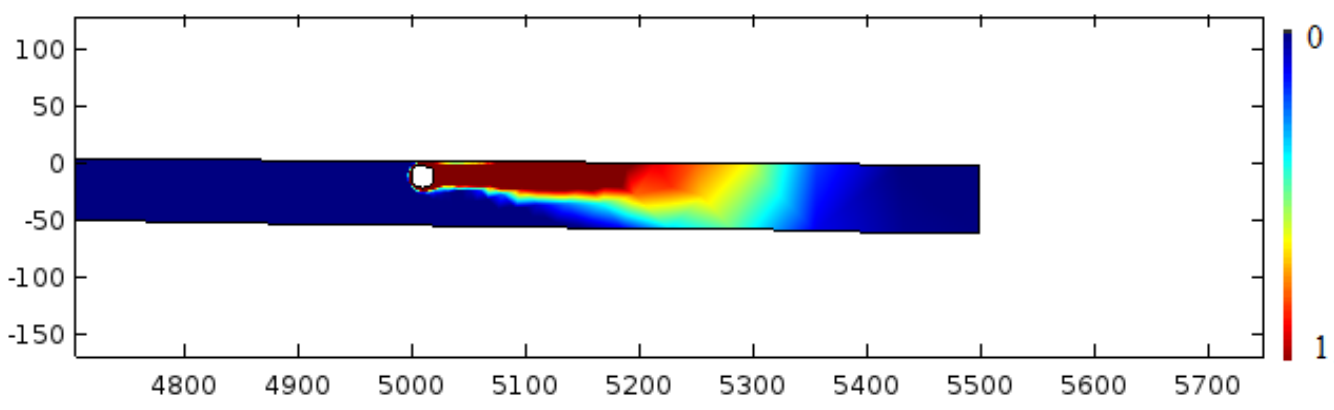

Figure 26: Concentration profile after 26 weeks of leakage, at $5000 \mathrm{~m}$ away from the dam.

$x$ direction. Whereas, near the sea, because of the lower input flow rate, the velocity magnitude is much lower, the diffusion effects are dominant over advection. Hence, the spreading of the contaminant is much slower near the sea side. Also, due to the large diffusion coefficient in the vertical direction, the spreading of the contaminant throughout the depth is very significant, which is more clearly observed for Scenario 2 , due to the dominance of diffusion.

The nature of the contaminant spreading profile is also investigated in the case of two leakages, at locations $900 \mathrm{~m}$ and $5000 \mathrm{~m}$ away from the dam respectively (Scenario 3). The contaminant concentration profile after 26 weeks is provided in 27. As in previous scenarios in Scenario 3 the spreading of the contaminant is much faster near the dam, whereas the contaminant extends over more depth near the sea. Effect of dominance of diffusion over advection is responsible for this behaviour. Thus, through the above model, given the location and time of leakage, the spread

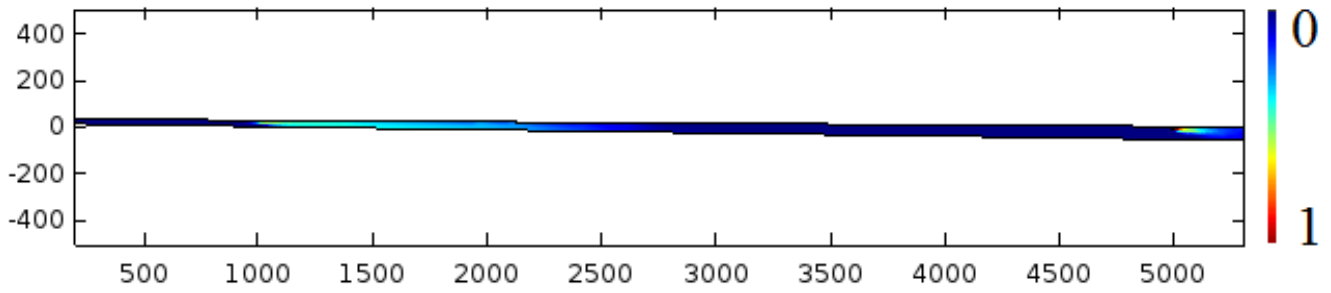

Figure 27: Concentration profile after 26 week of leakages at both $900 \mathrm{~m}$ and 5000 $m$ away from the dam.

and speed of a contaminant can be predicted to considerable accuracy. We have shown that advection has a much more prominent effect on the spreading of the contaminant. Hence, immediate shut-down of nearest recharge point can lead to restriction of contamination spreading in the $x$ direction.

\section{Conclusions and recommendations to the company}

Finally, we summarise our conclusions and formulate some recommendations for the Water Development Department (WDD). 
Firstly, in Section 3 we considered a two-dimensional model of the aquifer flow based on Darcy flow and then we used this model to compute an optimal recharge strategy for some scenarios of interest. One of the key results from this model was that in certain cases, if the optimal water recharge strategy is employed, there is a considerable reduction in the amount of wasted water compared to the current strategy where water is recharged and extracted in equal proportions. Therefore, the recommendation to the WDD is to consider exploring such optimal, mathematically driven strategies in order to recharge the aquifer with less water than with their current empirical approach. Also, even though the above model does not model the possibility of seawater intrusion a rough criterion for whether sea water will intrude in the aquifer was presented: if the water speed at the sea-aquifer boundary is greater than zero the risk of seawater intrusion is small.

In Section 4 we incorporated the effect of seawater intrusion, a topic of utmost interest by the WDD, by developing a more detailed mathematical model of the aquifer flow based on saturated-unsaturated groundwater flow modelling with variable water density. We used the open software tool SUTRASuite and evaluated different extraction/recharge scenarios. We found that this software works well and leads quite quickly to the identification of saltwater-seawater interface in the aquifer. Contrary to the model developed in Section 3 no significant simplifications are necessary when deriving the latter mathematical model and computational settings. The software is free available, and there is a large group of users that share their experiences on similar problems publicly, through their publications or in internet forums and so on. On the other hand, one cannot expect technical support for such open source software tools if some specific difficulties occur.

Computational models can greatly help when evaluating the effectiveness of recharge strategies for a given set of extraction wells or even to assess a threat caused by accidental leakage of contaminants. The most critical issue we see is that the transient modelling of the unsaturated zone in the aquifer requires appropriate state equations to model the water saturation and relative permeability. On the other hand this may be simplified if the water table is described without considering the unsaturated zone and it has to be determined with a different open source code, for example MODFLOW (which is compatible with ModelMuse) [5]. Some other difficulties to be resolved are mentioned at the end of Section 4. We note that the WDD already has several data and measurements that can be used to validate and further develop the models.

Next, in Section 5, we incorporated seawater intrusion in our model using the commercial code ANSYS FLUENT. Using such a powerful and user friendly software can speed up significantly an appropriate numerical modelling of recharge strategies for Germasogeia aquifer; it is however expensive.

Finally, in Section 6 we examined the second challenge posed by the WDD on contamination and we estimated the speed and spread of the contamination after an accidental leakage, using the commercial software COMSOL Multiphysics 5.2. We introduced an advection-diffusion equation for the contaminant concentration and determined the concentration profile of the contaminant at various locations, inside the fully saturated part of the aquifer. The spreading of the contaminant proceeds through advection by the aquifer water flow and by diffusion in both the longitudinal 
and the vertical direction. It was observed that the advection has a much more dominant effect on contaminant spreading than the diffusion. Another important result was that the location of the leakage affects the contaminant spreading significantly. If the leakage site is near the dam, the spreading is much more enhanced in the longitudinal direction and spreads much faster downstream, whereas for a leakage near the sea, diffusion is dominant over advection. In this case, spreading in the vertical direction is more prominent, and it does not spread much downstream. The model can predict the spreading of a contaminant, when the location and the time of leakage in the aquifer are known. Hence, it can be a useful tool to identify the portion of the aquifer which needs necessary attention for purification. To minimise the effect of contamination, it is advisable to shut down the immediate upstream recharge point. In this way, the effect of advection can be minimised, resulting in much lower contamination downstream.

For a more detailed study, some assumptions can be relaxed. Some of the improvements could be to take realistic values appropriate for the Germasogeia aquifer for the concentration, diffusivity and lateral dispersion of the contaminant, and implement in the models the precise location of recharge and extraction points, etc. Additionally, the duration that the contamination source is active could be varied. These considerations will improve the accuracy of the results. Also, more modelling work needs to be undertaken to couple this contamination model to sophisticated flow models, as those developed in Section 4 and 5.

Our work during the Study Group week resolved some aspects of the proposed challenges but there is strong potential for improvement in the sophistication and accuracy of our models. We recommend that the Water Development Department establish a long-term collaboration with mathematical modellers in order to explore further these interesting and important challenges. Such work could be undertaken by a $\mathrm{PhD}$ student over the period of 3-4 years or by more expert researchers in a shorter time frame. Moreover, an even larger project could be pursued and the work could be extended to the management of other aquifers in Cyprus. We are going to explore together with the WDD European funding on water management which could fund large water management projects.

\section{Acknowledgements}

The Organising Committee of ESGI125 would like to thank the Mathematics for Industry Network (MI-NET, www.mi-network.org), COST Action TD1409 for generous funding and support with the logistics of this first Study Group with Industry in Cyprus. Many thanks also to the Cyprus University of Technology that provided venue, organisational and funding support, as well as to all our other sponsors and supporters, and particularly KPMG Cyprus (major sponsor).

\section{References}

[1] Bear, J. and Verruijt, A., 1987. Theory and applications of transport in porous media. Modeling of groundwater flow and pollution, Dordrecht: Reidel. 
[2] C. J. Voss and W. R. Souza, Variable density flow and solute transport simulation of regional aquifers containing a narrow freshwater-saltwater transition zone, Wat. Res. Res. 23 (1987) 1851-1866.

[3] Henry H.R., Interfaces between salt water and fresh water in coastal aquifers, Water-Supply Paper 1613-C, Sea Water in Coastal Aquifers: C35-70, U.S. Geological Survey (1964).

[4] C. J. Voss and A.M. Provost, SUTRA - A Model for Saturated-Unsaturated, Variable-Density Ground-Water Flow with Solute or Energy Transport, U.S. Geological Survey, Water-Resources Investigations Report 02-4231 (2010) .

[5] Harbaugh, A.W., MODFLOW-2005, U.S. Geological SurveyTechniques and Methods 6-A16 (2005).

2005, the U.S. Geological Survey modular ground-water model - the GroundWater Flow Process: U.S. Geological Survey Techniques and Methods 6-A16.

[6] Fluent, A. (2009a). Ansys Fluent 12.0 - porous media flows. Available at http://www.afs.enea.it/project/neptunius/docs/fluent/html/ ug/node233.htm.

[7] Fluent, A. (2009b). Ansys Fluent 12.0 User's guide. Available at http:// users .ugent. be/ mvbelleg/flug-12-0.pdf.

[8] Issa, R. I. (1986). Solution of the implicitly discretised fluid flow equations by operator-splitting. Journal of computational physics, 62(1):40-65.

[9] Leonard, B. P. (1979). A stable and accurate convective modelling procedure based on quadratic upstream interpolation. Computer methods in applied mechanics and engineering, 19(1):59-98.

[10] Lide, D. R. (2004). CRC handbook of chemistry and physics, volume 85. CRC press.

[11] Patankar, S. (1980). Numerical heat transfer and fluid flow. CRC press.

[12] Sharqawy, M. H., Lienhard, J. H., and Zubair, S. M. (2010). Thermophysical properties of seawater: a review of existing correlations and data. Desalination and Water Treatment, 16(1-3):354-380.

[13] Ubbink, O. (1997). Numerical prediction of two fluid systems with sharp interfaces. PhD thesis, University of London PhD Thesis.

[14] Youngs, D. L. (1982). Time-dependent multi-material flow with large fluid distortion. Numerical methods for fluid dynamics, 24(2):273-285.

[15] P. G. Smith and P. Coackley, Diffusivity, tortuosity and pore structure of activated sludge, Water Res. 18 (1984) 117-122.

[16] J.M.P.Q. Delgado, Longitudinal and transverse dispersion in porous media, Chem. Eng. Res. Des. 85 (2007) 1245-1252. 
[17] W. P. Ball, Long-term sorption of halogenated organic chemicals by aquifer material. 2. intraparticle diffusion, Env. Sci. Technol. 25 (1991) 1237-1249.

[18] C. Li, Z. Zheng, X. Y. Liu, T. Chen, W. Y. Tian, L. H. Wang, C. L. Wang, C. L. Liu, The Diffusion of Tc-99 in Beishan Granite-Temperature Effect, World J. Nuclr. Sci. Technol. 3 (2013) 33-39.

[19] G. W. Sun, W. Sun, Y. S. Zhang, Z. Y. Liu, Relationship between chloride diffusivity and pore structure of hardened cement paste, J. Zhejiang Univ-Sci. A (Appl Phys Eng) 12 (2011) 360-367. 